\title{
A Review of Topology Optimisation for Fluid-Based Problems
}

\author{
Joe Alexandersen ${ }^{1, *(D)}$ and Casper Schousboe Andreasen 2 (D) \\ 1 Department of Technology and Innovation, University of Southern Denmark, 5230 Odense, Denmark \\ 2 Department of Mechanical Engineering, Technical University of Denmark, 2800 Kgs. Lyngby, Denmark; \\ csan@mek.dtu.dk \\ * Correspondence: joal@iti.sdu.dk
}

Received: 7 February 2020; Accepted: 27 February 2020; Published: 4 March 2020

\begin{abstract}
This review paper provides an overview of the literature for topology optimisation of fluid-based problems, starting with the seminal works on the subject and ending with a snapshot of the state of the art of this rapidly developing field. "Fluid-based problems" are defined as problems where at least one governing equation for fluid flow is solved and the fluid-solid interface is optimised. In addition to fluid flow, any number of additional physics can be solved, such as species transport, heat transfer and mechanics. The review covers 186 papers from 2003 up to and including January 2020, which are sorted into five main groups: pure fluid flow; species transport; conjugate heat transfer; fluid-structure interaction; microstructure and porous media. Each paper is very briefly introduced in chronological order of publication. A quantititive analysis is presented with statistics covering the development of the field and presenting the distribution over subgroups. Recommendations for focus areas of future research are made based on the extensive literature review, the quantitative analysis, as well as the authors' personal experience and opinions. Since the vast majority of papers treat steady-state laminar pure fluid flow, with no recent major advancements, it is recommended that future research focuses on more complex problems, e.g., transient and turbulent flow.
\end{abstract}

Keywords: topology optimisation; review paper; fluid flow; multiphysics; species transport; conjugate heat transfer; fluid-structure interaction; porous media

\section{Introduction}

The topology optimisation method originates from the field of solid mechanics, where it emerged from sizing and shape optimisation by the end of the 1980s. The seminal paper on topology optimisation is often quoted as being the homogenisation method by Bendsøe and Kikuchi [1]. Topology optimisation is posed as a material distribution technique that answers the question "where should material be placed?" or alternatively "where should the holes be?". As a structural optimisation method, it distinguishes itself from the more classical disciplines of sizing and shape optimisation, by the fact that there does not need to be an initial structure defined a priori. Having stated that, we define topology optimisation slightly wider in this context, as we include optimisation approaches in which the topology is allowed to or can change during the optimisation process. The review papers by Sigmund and Maute [2] and Deaton and Grandhi [3] give a general overview of topology optimisation methods and applications. Today, topology optimisation for solid mechanics is a mature technology that is widely available in all major finite element analysis (FEA) packages and even in many computer aided design (CAD) packages. The technology is utilised at the component design level in the automotive and aerospace industries. 
The ideas of the original methodology are extendable to all physics, where the governing equations can be described by a set of partial differential equations (PDEs). It has therefore in the post-2000 decades seen widespread application to a range of different physics, such as acoustics, photonics, electromagnetism, heat conduction, fluid flow, etc. [3].

When applied to fluid problems, the question should be rephrased from "where should the holes be?" to "where should the fluid flow?". The optimisation problem basically becomes a question of where to enforce relevant boundary conditions for the flow problem. This review paper is a survey of published papers containing topology optimisation of fluid flow problems and related fluid-based problems. It is the first to cover the entire history, from its very beginning to the current state of the art. There are two previous review papers dealing with two different subsets under the umbrella of fluid-based problems, namely microfluidics [4] and thermofluidics [5].

\subsection{Definitions for Inclusion}

In the following, the scope and limitations of the review and the applied definition for fluid-based problems are elaborated upon.

\subsubsection{Governing Equations}

The solved problems must include fluid flow, meaning that at least one governing equation for fluid flow must be solved, such as:

- Darcy, Forchheimer and Brinkman flow

- Stokes and Navier-Stokes flow

- Homogenised fluid equations

- Kinetic gas theory, Lattice Boltzmann and similar methods based on distributions

- Particle methods

Therefore, papers treating only hydrostatic fluid loading (Laplace equation for pressure) and acoustics (Helmholtz equation for sound pressure) are omitted. In addition to this, for fluid-structure interaction problems, where only the structural part is optimised (so-called "dry optimisation") has also been left out.

In addition to the governing equations for fluid flow, any number of additional physics can be solved. The additional physics can be uncoupled, loosely coupled (one-way) or fully coupled (two-way), as long as a fluid problem is included in the optimisation formulation in the form of the objective functional or constraints. Examples are:

- Species transport, e.g., microfluidic mixers,

- Reaction kinetics, e.g., ion transport in flow batteries,

- Temperature, e.g., heat exchangers,

- Structural mechanics, e.g., fluid-structure interaction.

1.1.2. Literature Search

In order to collect relevant literature for this review, a literature search was performed using Google Scholar based on the keyword combinations of "topology optimization" with the following:

- fluid flow

- conjugate heat transfer

- convection

- fluid structure interaction

- microstructure

- homogenization 
In addition to the above, reverse tracking was used of citations of the seminal papers in the area, as well as relevant references in the papers from the search. Only journal publications have been included, except when important contributions have been made in available conference proceedings.

\subsubsection{Optimisation Methodology}

A broad and open definition of topology optimisation is used herein. The presented methodologies must be capable of handling topological changes in three dimensions. That is, the methods should in a three-dimensional version be capable of handling large design changes and topological changes by creating, removing and merging holes. This can be difficult for some representations, especially in two dimensions, where auxiliary information such as topological derivatives is necessary for the creation of holes/structure. Pure shape optimisation, where only small modifications of the fluid-solid or fluid-void interface is possible, is not included in this review.

However, there might not be much need for changes in topology for most two-dimensional fluid flow problems. Due to the nature of fluid flow and the obvious objective of minimising power dissipation (or pressure drop), there is a desire to minimise the number of flow channels, i.e., only a single flow path is needed and the interface shape is modified. The need for topology optimisation does arise when other objectives, such as flow uniformity or diodicity, are considered and when the fluid flow is coupled to additional physics, such as e.g., heat transport.

The design representation used for topology optimisation of fluid-based problems is in general similar to those applied within the area of solid mechanics [2,6]. Figure 1 shows the three general options for representing the design. The first representation is an explicit boundary representation based on a body-fitted mesh adopting to the nominal geometry shown in red. If the design is changed, boundary nodes must be moved and the mesh must be updated or the domain must be entirely re-meshed if large changes are applied. The second representation is that of the density-based methods, which also includes level set methods where a smooth Heaviside projection is applied together with interpolation of material properties (so-called Ersatz material methods). The flow is penalised in the solid (black) domain, typically by modelling it as a porous material with very low permeability. The third representation is that of surface-capturing level set methods, where surface-capturing discretisation methods, e.g., the extended finite element method (X-FEM), where the cut elements are integrated using a special scheme and the interface boundary conditions are imposed, e.g., using stabilised Lagrange multipliers or a stabilised Nitsche's method.

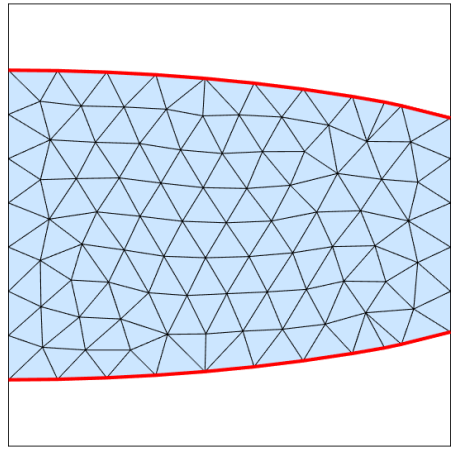

(a)

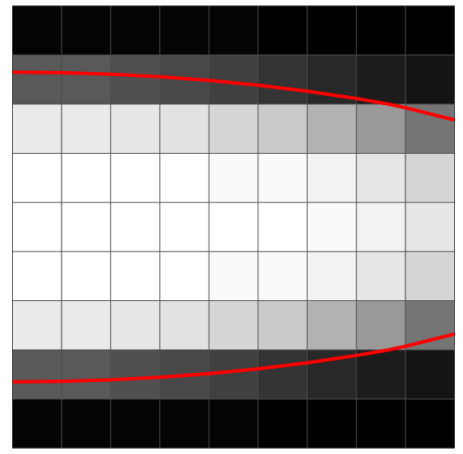

(b)

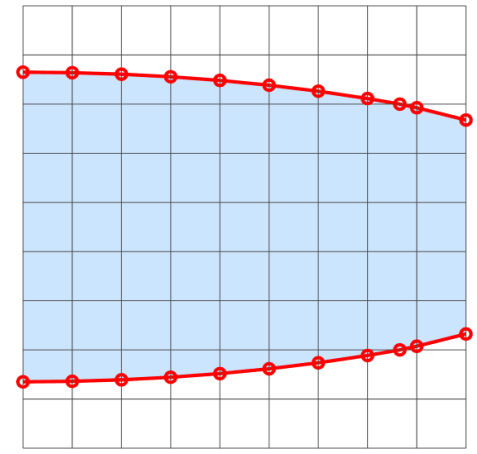

(c)

Figure 1. Fluid nozzle illustrating the basic differences among design representations in topology optimisation: (a) explicit boundary representation (body fitted mesh); (b) density/ersatz material based representation; (c) level set based X-FEM/cutFEM representation.

The explicit boundary methods represent the physics well, but moving nodes and adaption of the mesh are non-smooth operations and this might pose difficulties in advancing the design for the optimiser. Furthermore, regularisation of the interface is necessary and, in case of full re-meshing, it might be difficult to assure high quality elements, while limiting the computational time. 
The density-based methods are strong regarding the ability to change topology and change the design dramatically, due to the design sensitivities being distributed over a large part of the domain. The cost of introducing the design is relatively low, as only an extra term needs to be integrated, with no special interface treatment being necessary. However, there are problems such as choosing proper interpolation schemes for material properties and, in the case of fluids, a large enough penalisation of the flow in solid regions. The velocity and pressure fields are present in the entire domain, both solid and fluid regions, which may cause spurious flows and leaking pressure fields, if not penalised sufficiently.

For the surface-capturing methods, the well defined and crisp interface makes it easy to introduce interface couplings between different physics, e.g., for fluid-structure interaction problems. As for any level set method, due to the nature of the method, the design sensitivities are located only at the interface. This means that design changes can only propagate from the interface and no new holes appear automatically. This is often relieved by using an initial design with many holes or by introduction of a hole nucleation scheme, e.g., using topological derivatives.

The above methods will not be described in detail, but the readers are referred to the descriptions in the individual papers of the review and the general overview in the review papers by Sigmund and Maute [2] and van Dijk et al. [6].

\subsection{Layout of Paper}

The included papers are divided into different subsets based on the number and complexity of the physics involved. The layout of this paper is accordingly divided into sections.

The literature review is presented in Section 2. Section 2.1 covers pure fluid flow problems divided into steady laminar flow (Section 2.1.1), unsteady flow (Section 2.1.2), turbulent flow (Section 2.1.3) and non-Newtonian fluids (Section 2.1.4). Section 2.2 considers species transport problems. Section 2.3 deals with conjugate heat transfer problems, where the thermal field is modelled in both solid and fluid domains, divided according to the type of cooling into forced convection (Section 2.3.1) and natural convection (Section 2.3.2). Section 2.5 considers both material microstructures (Section 2.5.1), where effective material parameters are optimised, and porous media (Section 2.5.2), where homogenised properties are used to optimise a macroscale material distribution. Section 2.4 covers fluid-structure interaction (FSI) problems with the fluid flow loading a mechanical structure.

After the literature review, Section 3 performs a quantitative analysis of the included papers and Section 4 presents recommendations for future focus areas for research within topology optimisation of fluid-based problems. Finally, Section 5 briefly concludes the review paper.

\section{Literature Review}

In the following, the papers are grouped based on their most advanced example, if the work covers both simple and extended applications. Furthermore, the papers are presented in chronological order based on the date that the papers were available online, as this gives a better representation of the order than official date of the final issue, since that may well trail the online publication significantly and differently from paper to paper.

\subsection{Fluid Flow}

This section covers the majority of the papers included in the review paper, namely pure fluid flow problems. The section is divided into subsections covering steady laminar flow, unsteady flow, turbulent flow, microstructure and porous media.

\subsubsection{Steady Laminar Flow}

Borrvall and Petersson [7] published the seminal work on fluid topology optimisation in 2003. They presented an in-depth mathematical basis for topology optimisation of Stokes flow. The design parametrisation is based on lubrication theory, leveraging the frictional resistance between parallel 
plates. Solid domains are approximated by areas with vanishing channel height. By designing the spatially-varying channel height, it is possible to achieve fluid topologies that dictate where flow channels minimising the dissipated energy are placed. This parametrisation was extended to Navier-Stokes flow by Gersborg-Hansen et al. [8] in 2005. Both sets of authors note the similarity of the obtained equations with that of a Brinkman-type model of Darcy's law for flow through a porous medium. Here, solid domains are approximated by areas with a very low permeability. When treating two-dimensional problems of a finite depth, it makes sense to use the lubrication theory approach, since this ensures the out-of-plane viscous resistance due to finite channel width being taken into account in the fluid parts of the domain. However, for three-dimensional problems, the lubrication theory approach loses its physical meaning, whereas the porous media approach carries over without any issues.

Evgrafov [9] investigated the limits of porous materials in the topology optimisation of Stokes flow using mathematical analysis, complementing the analysis presented originally by Borrvall and Petersson [7]. Olesen et al. [10] presented a high-level programming-language implementation of topology optimisation for steady-state Navier-Stokes flow using the fictitious porous media approach. Guest and Prévost [11] took a different approach to the previous work and modelled the solid region as areas with Darcy flow of low permeability surrounded by areas of Stokes flow using an interpolated Darcy-Stokes finite element. Evgrafov [12] investigated the theoretical foundation and practical stability of the penalised Navier-Stokes equations going to the limit of infinite impermeability, showing that the problem is ill-posed for increasing impermeability of solid regions and that slight compressibility and filters can ensure solutions. Wiker et al. [13] treated problems with separate regions of Stokes and Darcy flow, similar to Guest and Prévost [11], but with a finite impermeability in order to simulate actual flow in porous media for a mass flow distribution problem. Pingen et al. [14] used the Lattice Boltzmann method (LBM) as an approximation of Navier-Stokes flow. Their work included the first three-dimensional result on a very coarse discretisation. Aage et al. [15] were the first to treat truly three-dimensional problems using shared-memory parallelisation, allowing them to optimise large scale Stokes flow problems. Bruns [16] highlighted the similarity of the previous approaches to that of a penalty formulation of imposing no-flow boundary conditions. Specifically, a volumetric penalty term is used to impose no-flow inside solid regions. This interpretation has become widespread through the years, as the physical relevance of the design parametrisation has lost interest and the strictly numerical view has gained popularity. Duan et al. [17-19] presented the first application of a variational level set method to fluid topology optimisation, producing similar designs to those previously obtained using density-based methods. Evgrafov et al. [20] performed a theoretical investigation into the use of kinetic theory to approximate Navier-Stokes for fluid topology optimisation. Othmer [21] derived a continuous adjoint formulation for both topology and shape optimisation of Navier-Stokes flow for implementation into the finite volume solver OpenFOAM. Although results for turbulent flow are presented, the approach is herein not considered "fully turbulent" due to the assumption of "frozen turbulence" (not taking the turbulence variables into account in the sensitivity analysis). Pingen et al. [22] discuss efficient methods for computation of the design sensitivities for LBM based methods and apply topology optimisation to a Tesla-type valve design problem. Zhou and Li [23] presented a variational level set method for Navier-Stokes flow excluding elements outside of the fluid region in order to increase accuracy of the no-slip boundary condition, but increasing book-keeping through updating the fluid mesh every design iteration. Pingen et al. [24] formulated a parametric level set approach using LBM to model the fluid flow. In contrast to the previous variational level set methods, gradient-based mathematical programming is used to update the level set function rather than using the traditional Hamilton-Jacobi equation. Similarly to Zhou and $\mathrm{Li}$ [23], Challis and Guest [25] proposed a variational level set method where only discrete fluid areas occur. This removes the need for interpolation schemes, and, by discarding the degrees-of-freedom in the solid, they are able to solve large three-dimensional problems at a reduced cost. Kreissl et al. [26] presented a generalised shape optimisation approach using an 
explicit level set formulation, where the nodal values of the level set are explicitly varied using a mathematical programming approach in contrast to variational [17-19,23,25] and parametric [24] level set formulations. Furthermore, they use a geometric boundary representation that enforces no-slip conditions along the fluid-solid interface using the LBM. Liu et al. [27] optimised fluid distributors with multiple flow rate equality constraints. Okkels et al. [28] elaborated on the lubrication theory approach to design the height profile of the inlet of a bio-reactor minimising the pressure drop while maintaining a uniform flow through the reactor. While most of the previous works treated energy dissipation or pressure drop, Kondoh et al. [29] presented a density-based topology optimisation formulation for drag minimisation and lift maximisation of bodies using body force integration. Building on their previous work, Kreissl and Maute [30] developed an explicit level set method accurately capturing the boundary using the extended finite element method (X-FEM). Deng et al. [31] presented a density-based method for both steady and unsteady flows driven by gravitational, centrifugal and Coriolis body forces. Deng et al. [32] also proposed an implicit variational level set method for steady Navier-Stokes flow with body forces.

The work by Aage and Lazarov [33] is not focused on fluids, but rather presents a parallel framework for large-scale three-dimensional topology optimisation. However, they use a Stokes flow driven manifold distributor as an application using 3.35 million DOFs for the fluid problem. Evgrafov [34] presented a state space Newton's method for minimum dissipated energy of Stokes flow, which outperforms the traditional first order nested approaches significantly for specific problems. Romero and Silva [35] applied a density-based approach to the design of rotating laminar rotors by including the centrifugal and Coriolis forces. Yaji et al. [36] formulated a level set based topology optimisation of steady flow using the LBM and a continuous adjoint sensitivity analysis based on the Boltzmann equation. Liu et al. [37] presented a density-based method based on the LBM using a discrete adjoint sensitivity analysis posed in the moment space. Yonekura and Kanno [38] suggested to use transient information for steady state optimisation using the LBM by modifying the design during a single transient solve. Liu et al. [39] proposed a re-initialisation method for level set based optimisation using a regular mesh for the level set equation and an adaptive mesh for the fluid analysis. Duan et al. [40] presented an adaptive mesh method for density-based optimisation using an optimality criteria (OC) algorithm. Extending his previous work, Evgrafov [41] presented a Chebyshev method for topology optimisation of Stokes flow achieving locally cubic convergence for specific problems. Garcke and Hecht [42] performed an in-depth mathematical analysis of a phase field approach to topology optimisation of Stokes flow. Lin et al. [43] applied a density-based approach to the design of fixed-geometry fluid diodes, manufacturing the designs and verifying their performance using an experimental setup. Building on their previous formulation and analysis, Garcke et al. [44] provided numerical results for Stokes flow using their phase field approach and adaptive mesh refinement. Duan et al. [45] presented an Ersatz material based implicit level set method showing clear connections to density-based methods through the material distribution. Sá et al. [46] applied the concept of topological derivatives to fluid flow channel design.

Yoshimura et al. [47] proposed a gradient-free approach using a genetic algorithm to update a very coarse design using a Kriging surrogate model coupled to an immersed method known as the Building-Cube Method. Pereira et al. [48] applied a density-based approach to Stokes flow using polygonal elements and supplying a freely available code for fluid topology optimisation. Duan et al. [49] presented an adaptive mesh method to an Ersatz-material level set based approach for Navier-Stokes flow. Kubo et al. [50] used a variational Ersatz-material level set method to design manifolds for flow uniformity in microchannel reactors. Jang and Lee [51] maximise the acoustic transmission loss in a chamber muffler with a constraint on the reverse-flow power dissipation modelled using the Navier-Stokes equations. Koch et al. [52] proposed a method for automatic conversion from two-dimensional Ersatz-based level set topology optimisation to NURBS-based shape optimisation. Sato et al. [53] applied density-based topology optimisation to the design of no-moving parts fluid valves using a Pareto front exploration method. Sá et al. [54] further extended the work 
in [46] to rotating domains. Yonekura and Kanno [55] extended their previous approach for updating the design during the computation of an unsteady flow field to a level set based method. Dai et al. [56] presented a piecewise constant Ersatz-material level set method, which essentially reduces it to a density-based method. Shen et al. [57] formulated a three-phase interpolation model in Darcy-Stokes flow for optimising fluid devices with Stokes flow, Darcy flow and solid domains. Deng et al. [58] used an Ersatz-material level set method to optimise two-phase flow, using with a phase field approach for the fluid-fluid interface. Garcke et al. [59] extended their phase field approach to Navier-Stokes flow, presenting both in-depth mathematical analysis and optimisation results for minimum drag and maximum lift problems. Alonso et al. [60] used a density-based approach to design laminar rotating swirl flow devices using a rotating axisymmetric model.

Jensen [61] proposed to use anisotropic mesh adaptation for density-based optimisation of Stokes flow, demonstrating that this allows for efficiently resolving the physical length scale related to very high Brinkman penalisation terms. Sá et al. [62] applied density-based optimisation to the design of a small scale rotary pump considering both energy dissipation and vorticity with experimental verification of the design performance. Zhou et al. [63] presented an integrated shape morphing and topology optimisation approach based on a mesh handling methodology called a deformable simplicial complex (DSC). Shin et al. [64] used a 2D axisymmetric model at moderate Reynolds numbers to optimise a vortex-type fluid diode that is postprocessed and verified by simulation under actual flow conditions and turbulence. Yonekura and Kanno [65] proposed a heuristic approximation of the Hessian matrix for fast density-based optimisation using the LBM. Behrou et al. [66] presented a methodology for adaptive explicit no-slip boundary conditions with a density-based method for laminar flow problems with mass flow constraints, adaptively removing elements in the solid regions. Alonso et al. [67] applied density-based optimisation to the design of Tesla-type centrifugal pumps without blades. Lim et al. [68] applied a density-based method to the design of vortex-type passive fluidic diode valves for nuclear applications. Sato et al. [69] presented a topology optimisation method for rarefied gas flow problems covering both gas and solid domains using the LBM. Gaymann et al. [70] applied a density-based method to the design of fluidic diode valves in both two- and three-dimensions at medium-to-high Reynolds numbers. Gaymann and Montomoli [71] applied deep neural networks and Monte Carlo Tree search to an absurdly coarse design grid.

\subsubsection{Unsteady Flow}

All of the previous works consider steady-state flow problems. However, not all fluid flows develop a steady state and there are situations where the unsteady motion can be exploited by the design. This could either be due to transients in an onset flow or due to vortex shedding from an obstacle. It should be noted that some discretisation methods, e.g., lattice Boltzmann methods, are of a transient nature; however, the papers are categorised based on the use of a time-dependent objective functional and sensitivity analysis. Thus, if only the final state solution is used to update the design, it is considered steady state and not included in this section.

Kreissl et al. [72] presented the first work treating density-based topology optimisation for unsteady flow, using a discrete transient adjoint formulation and applied to the design of a diffuser and an oscillating flow manifold. They highlighted some difficulties encountered using a standard density approach combined with a stabilised finite element formulation. A few months later, Deng et al. [73] also presented density-based topology optimisation for unsteady flow, but using a continuous transient adjoint formulation. They optimised a wide arrangement of problems including oscillating manifold flows. Deng et al. [31] extended their work to both steady and unsteady flows driven by gravitational, centrifugal and Coriolis body forces. Abdelwahed and Hassine [74] introduced analysis and application of the topological gradient method for non-stationary fluid flows. Nørgaard et al. [75] presented topology optimisation of what can be considered the first truly unsteady flow problems, considering oscillating flow over multiple periods for both obstacle reconstruction and design of an oscillating pump using the LBM. Villanueva and Maute [76] formulated a CutFEM discretised explicit level set 
method to the design of two- and three-dimensional flow for both steady-state and fully transient problems. Although the use of a surface-capturing scheme, they show that there is still a penaltyand mesh-dependent mass loss through the interface. Chen et al. [77] presented a local-in-time approximate discrete adjoint sensitivity analysis for unsteady flow using the LBM. They approximate the true time-dependent adjoint equations by splitting the time series into subintervals, rather than the full time series forward and then the full time series backwards. This significantly reduces the storage requirement but introduces an approximation error. Nørgaard et al. [78] discussed applications of automatic differentiation for topology optimisation, demonstrating their approach on an unsteady oscillating pressure pump. This was obtained using LBM and the design seems to rely on the slightly compressible behaviour of the fluid model. Sasaki et al. [79] presented fluid topology optimisation using a particle method for the first time. Specifically, they use the transient moving particle semi-implicit (MPS) method allowing them to treat free surface fluid flows without explicit surface tracking.

\subsubsection{Turbulent Flow}

All of the above fluid flow papers assume laminar fluid flow, whereas turbulent flow has only been treated in a few publications. Turbulence is inherently time-dependent, but current works on topology optimisation of turbulent flow restrict themselves to the steady-state time-averaged approximation of turbulence, namely the Reynolds-Averaged Navier-Stokes (RANS) equations.

In the work by Othmer [21], turbulence is in the model, but the influence on the design sensitivities is neglected. Kontoleontos et al. [80] presented the first work on topology optimisation of turbulent flow, including the Spalart-Allmaras turbulence model in their continuous adjoint sensitivity analysis. For a shape optimisation example, they showed that the typical "frozen turbulence" assumption produces sensitivities of the incorrect sign in some cases. Yoon [81] presented a discrete adjoint approach to density-based optimisation of turbulent flow problems using the Spalart-Allmaras turbulence model and a modified wall equation. However, the meshes used are much too coarse to capture turbulence properly. Dilgen et al. [82] demonstrated the application of automatic differentiation for obtaining exact sensitivities for density-based topology optimisation of large scale two- and three-dimensional turbulent flow problems, using the one-equation Spalart-Allmaras model and the two-equation $\mathrm{k}-\omega$ model. As Kontoleontos et al. [80] did for shape optimisation, they demonstrated that the "frozen turbulence" assumption gives inexact sensitivities for topology optimisation, even with the incorrect sign for some cases. Yoon [83] used a $k-\epsilon$ model, analogous to the model applied [82], to design 2D flow components minimising turbulent energy i.e., minimising noise.

\subsubsection{Non-Newtonian Fluids}

In the preceding works, the fluids are all assumed to be Newtonian. However, treating more sophisticated fluids, including e.g., long polymer chains or blood cells, calls for implementation of non-Newtonian fluids, which have nonlinear behaviour of the viscosity. There are a wide variety of models that can be applied and a few have been implemented for use in a topology optimisation context.

Pingen and Maute [84] applied topology optimisation to non-Newtonian flows for the first time, using a density-based LBM formulation and a Carreau-Yasuda model for shear-thinning fluids. Ejlebjerg Jensen et al. [85] optimised viscoelastic rectifiers using a non-Newtonian fluid model based on dumbbells in a Newtonian solvent, which introduced a memory in the fluid. Jensen et al. [86] considered the bi-stability behaviour for a crossing between two viscoelastic fluids. Hyun et al. [87] suggested a density-based formulation for minimising wall shear stress by considering shear thinning non-Newtonian effects. Zhang and Liu [88] applied a level set based approach to minimise flow shear stress in arterial bypass graft designs, where the blood flow is modelled using a steady non-Newtonian modified Cross model. Zhang et al. [89] used an explicit boundary-tracking level set method with remeshing to optimise micropumps for non-Newtonian power-law fluids. Romero and Silva [90] 
extended their previous work [35] to cover non-Newtonian fluids and compare it to the Newtonian case. Dong and Liu [91] proposed a bi-objective formulation for the design of asymmetrical fixed-geometry microvalves for non-Newtonian flow.

\subsection{Species Transport}

In this section, the included papers are focused on a transport of matter or species due to the presence of a fluid. The transported matter does not necessarily need to be modelled itself, as long as the objective of the optimisation is related to the transport.

Okkels and Bruus [92] coupled a convection-reaction-diffusion equation to the fluid flow to model catalytic reactions, distributing the porous catalytic support to maximise the mean reaction rate of the microreactor. Andreasen et al. [93] used a convection-diffusion equation to model and optimise microfluidic mixers, in which well-known design elements such as herring-bones and slanted grooves appeared automatically. Gregersen et al. [94] applied topology optimisation to an electrokinetic model in order to maximise the net induced electroosmotic flow rate. Schäpper et al. [95] used more advanced reaction-kinetics using multiple convection-diffusion type equations to optimise microbioreactors. Kim and Sun [96] optimised the gas distribution channels in automotive fuel cells. Makhija et al. [97] optimised a passive micromixer using a porosity model for LBM. Deng et al. [98] used a physical model similar to [93] but omits the pressure constraint and use a quasi-Newton approach optimised three-dimensional and extruded two-dimensional microfluidic mixers. Makhija and Maute [99] introduced an explicit level set optimisation methodology using an X-FEM-based hydrodynamic Boltzmann model including transport. The ability to eliminate the spurious diffusion in void areas, especially dubious when modeling species concentration, is highlighted. Oh et al. [100] used the Navier-Stokes and a convection-diffusion equation to model and optimise the osmotic permeate flux over a membrane wall. Chen and $\mathrm{Li}$ [101] optimised micromixers under the assumption that reverse flow structures [8] inserted in a microchannel increases the mixing. Hyun et al. [102] designed repeating units for sorting particles using principles in deterministic lateral displacement. Andreasen [103] used a density-based framework to design dosing units of a secondary fluid utilising the inertia of the driving fluid. Yaji et al. [104] presented an optimisation of vanadium redox flow batteries by including a reaction term depending on the local flow speed and concentration level in a two-dimensional setting. Guo et al. [105] presented a methodology to model and optimise pure convection-dominated transport using a Lagrangian mapping method. Only the Navier-Stokes equations are approximated by FEM, while the Lagrangian transport is modelled cross-section-wise. Behrou et al. [106] presented a density-based approach for the design of proton exchange membrane fuel cells using a depth-averaged two-dimensional approximation of reactive porous media flow. Chen et al. [107] extended their previous work [104] to three-dimensional problems. Dugast et al. [108] used a level set method and the LBM to maximise the reaction in a square reactor and investigated the problem for a range of flow situations.

\subsection{Conjugate Heat Transfer}

Conjugate heat transfer is when the coupled heat transfer between a solid and the surrounding fluid is considered, with the temperature field of both of interest. Thus, in order to model conjugate heat transfer, it is necessary to build the thermal transport on top of the fluid flow model. Conjugate heat transfer is generally divided into groups based on the heat transfer mechanism in the fluid.

Figure 2 shows the three main heat transfer mechanisms: forced convection, where the flow is actively driven by a pump, fan or pressure-gradient; natural convection, where the flow happens passively from the natural density variations due to temperature differences; and diffusion where heat is transferred through a stagnant fluid through diffusion. Only the first two are considered in this review, since they include fluid motion modelled through fluid flow equations. 


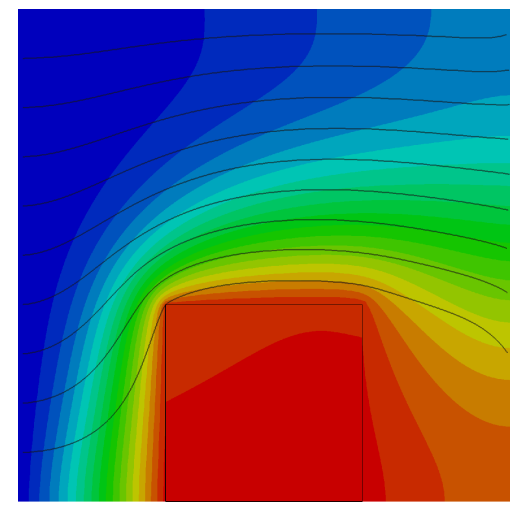

(a) Forced convection

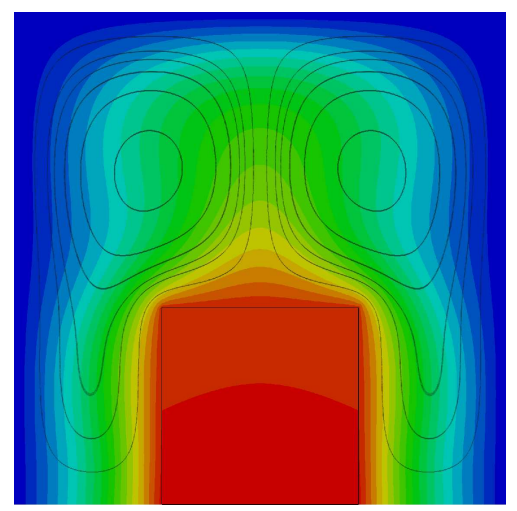

(b) Natural convection

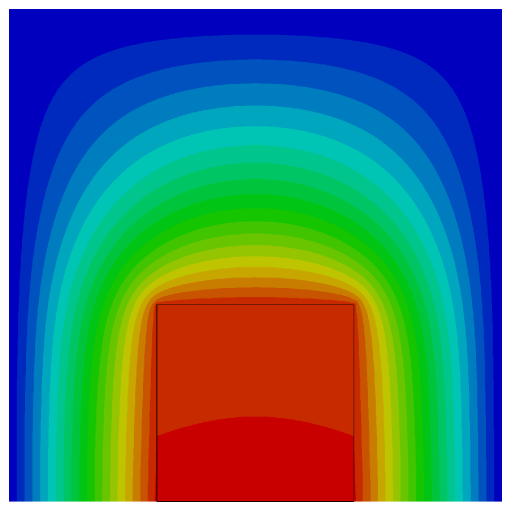

(c) Diffusion

Figure 2. Illustration of a metallic block subjected to different heat transfer mechanism in the surrounding fluid. (a) shows forced convection with a cold flow entering at the left-hand side; $(\mathbf{b}, \mathbf{c})$ show natural convection and pure diffusion, respectively, due to cold upper and side walls. Reproduced with permission from Alexandersen et al. [109].

\subsubsection{Forced Convection}

Dede [110] and Yoon [111] presented the first works on topology optimisation of forced convection at almost the same time. Dede [110] used the commercial finite element analysis (FEA) software COMSOL to optimise both conduction and conjugate heat transfer problems. Yoon [111] presented a two-dimensional formulation, treating heat sink problems, as well as flow focusing in order to cool specific points. Thereafter, Dede [112] applied topology optimisation to design multipass branching microchannel heat sinks for electronics cooling. McConnell and Pingen [113] presented a two-layer pseudo-3D topology optimisation formulation based on the lattice Boltzmann method (LBM). Kontoleontos et al. [80] presented a continuous adjoint formulation for fluid heat transfer using the Spalart-Allmaras turbulence model and the impermeability directly as the design variable. However, the presented examples are not true conjugate heat transfer problems, since the solid temperature is predefined and enforced through a penalty approach, rather than modelling the solid temperature alongside the fluid temperature. Matsumori et al. [114] presented topology optimisation for forced convection heat sinks under constant input power. They interpolated the heat source to only be active in the solid and investigated both temperature-independent and -dependent sources. Marck et al. [115] investigated a multiobjective optimisation problem considering both fluid and thermal objectives using a finite volume-based discrete adjoint approach. Koga et al. [116] presented the development of an active cooling heat sink device using topology optimisation, which was manufactured and experimentally tested. However, they used a two-dimensional Stokes flow model to optimise for a three-dimensional turbulent application. In 2015, Yaji et al. [117] published three-dimensional results for forced liquid-cooled heat sinks using an Ersatz-material level set approach. Next, Yaji et al. [118] presented a topology optimisation method using the Lattice Boltzmann Method (LBM) incorporating a special sensitivity analysis based on the discrete velocity Boltzmann equation. Łaniewski Wołłk and Rokicki [119] treated large three-dimensional problems using a discrete adjoint formulation for the LBM implemented for multi-GPU architectures. Qian and Dede [120] introduced a constraint on the tangential thermal gradient around discrete heat sources with the goal of reducing thermal stress due to non-uniform expansion. Yoshimura et al. [47] proposed a gradient-free approach using a genetic algorithm and a Kriging surrogate model coupled to an immersed method known as the Building-Cube Method. Haertel and Nellis [121] developed a plane two-dimensional fully-developed flow model for topology optimisation of air-cooled heat sinks. Pietropaoli et al. [122] used the impermeability as the design variable to optimise internal channels.

In 2018, Zhao et al. [123] used a Darcy flow model for topology optimisation of cooling channels. Qian et al. [124] optimised active cooling flow channels for cooling an active phased array antenna with 
many discrete heat sources. Sato et al. [125] used an adaptive weighting scheme for the multiobjective topology optimisation of active heat sinks. Yaji et al. [126] applied a local-in-time approximate transient adjoint method for topology optimisation of large scale problems with oscillating inlet flow. Haertel et al. [127] presented a pseudo-3D model for extruded forced convection heat sinks, actually considering the chip temperature by coupling a thermofluid design layer to a conductive base plate layer. Almost simultaneously, Zeng et al. [128] published a similar two-layer model for an air-cooled mini-channel heat sink, where the connection between the layers is tuned using full three-dimensional simulations of a reference heat sink design. Furthermore, Zeng et al. [128] manufactured and experimentally validated the performance of their optimised designs. Dilgen et al. [129] presented the first full conjugate heat transfer model for density-based topology optimisation of turbulent systems. In contrast to Kontoleontos et al. [80], the temperature field of the solid is modelled, thus rendering it true conjugate heat transfer. Furthermore, Dilgen et al. [129] treat large-scale three-dimensional problems comparing their thermal performance to equivalent two-dimensional designs. Ramalingom et al. [130] proposed a sigmoid interpolation function for mixed convection problems. Dugast et al. [131] applied a level set based approach in combination with the LBM to a variety of thermal control problems. Santhanakrishnan et al. [132] performed a comparison of density-based and Ersats-material level set topology optimisation for three-dimensional heat sink design using the commerical FEA software COMSOL. However, the designs, both density and level set based, show clear signs of being unconverged with unphysical designs and, thus, the study must be rendered inconclusive. Sun et al. [133] used density-based topology optimisation to generate guiding channels for an enhanced air-side heat transfer geometry in fin and tube heat exchangers. Lv and Liu [134] applied a density-based method to the design of a bifurcation micro-channel heat sink, comparing them to reference designs.

In 2019, Pietropaoli et al. [135] extended their previous work to three-dimensional internal coolant systems. Makhija and Beran [136] presented a concurrent optimisation method using a shape parametrisation for the external shape and a density-based parametrisation for the internal geometry. Subramaniam et al. [137] investigated the inherent competition between heat transfer and pressure drop. Yu et al. [138] applied a geometry projection method called moving morphable components (MMC) to the design of two-dimensional problems allowing for explicit feature size contol. Zhang and Gao [139] presented a density-based approach for optimising non-Newtonian fluid based thermal devices. Kobayashi et al. [140] used topology optimisation to design extruded winglets for fin-and-tube heat exchangers. Zeng and Lee [141] extended their previous work to the design of liquid-cooled microchannel heat sinks with in-depth numerical and experimental investigations. Jahan et al. [142] designed conformal cooling channels for plastic injection molds using a two-dimensional simplification. Yan et al. [143] developed a two-layer plane model based on analytical derivations and assumptions of the out-of-plane distribution for optimising microchannel heat sinks. Tawk et al. [144] proposed a density-based approach for optimising heat exchangers with two seperate fluids and a solid. Lundgaard et al. [145] presented a density-based methodology for distributing sand and rocks in thermal energy storage systems modelled by a transient Darcy's law coupled to heat transfer. Li et al. [146] applied a multi-objective density-based method to the design of liquid-cooled heat sinks, presented both extensive numerical and experimental comparisons to reference designs. Dong and Liu [147] applied topology optimisation to air-cooled microchannel heat sinks with discrete heat sources. Yaji et al. [148] suggested a multifidelity approximation framework to optimise turbulent heat transfer problems using a low-fidelity laminar flow model as the driver. Hu et al. [149] applied a density-based approach to optimisation of a microchannel heatsink with an in-depth comparison to a reference design with straight channels.

\subsubsection{Natural Convection}

Alexandersen et al. [109] presented the first work on topology optimisation of natural convection problems, using a density-based approach for optimising both heat sinks and buoyancy-driven 
micropumps. On the contrary, Coffin and Maute [150] used an explicit level set method combined with the extended finite element method (X-FEM) for both steady-state and transient natural convection cooling problems. Alexandersen et al. [151] extended their initial paper to large-scale three-dimensional heat sink problems using a parallel framework allowing for the optimisation of problems with up to 330 million DOFs. Pizzolato et al. [152] applied topology optimisation to the design of fins in shell-and-tube latent heat thermal energy storage, including the temperature-dependent latent heat coupled with natural convection using a time-dependent formulation. Alexandersen et al. [153] applied their previously developed framework to optimise the design of passive coolers for light-emitting diode (LED) lamps showing superior performance compared to reference lattice and pin fin designs. Ramalingom et al. [130] proposed a sigmoid interpolation function for mixed convection problems. Lazarov et al. [154] performed an experimental validation of the optimised designs from Alexandersen et al. [153] using additive manufacturing in aluminium, showing good agreement with numerical results and highlighting the superiority of topology-optimised designs. Lei et al. [155] continued this work and used investment casting to experimentally investigate a larger array of heat sink designs comparing them to optimised pin fin designs. Saglietti et al. [156] presented topology optimisation of heat sinks in a square differentially heated cavity using a spectral element method. In order to reduce the computational cost, Asmussen et al. [157] suggested an approximate flow model to that originally presented by Alexandersen et al. [109], by neglecting intertia and viscous boundary layers. Pizzolato et al. [158] extended their previous work to maximise the performance of multi-tube latent heat thermal energy storage systems, investigating many different working conditions. Ramalingom et al. [159] applied their previous method to multi-objective optimisation of mixed and natural convection in a asymmetrically-heated vertical channel. Pollini et al. [160] extended the work of Asmussen et al. [157] to large-scale three-dimensional problems, producing results comparable to those of Alexandersen et al. [151] with a computational time reduction of $80-95 \%$ in terms of core-hours.

\subsection{Fluid-Structure Interaction}

In this section, the advances within topology optimisation of fluid-structure interaction (FSI) problems are discussed.

Figure 3 shows the types of design modifications possible for FSI problems. Dry optimisation only changes the internal structure, keeping the solid-fluid interface constant. Wet optimisation modifies the solid-fluid interface and topology. Since this review paper is focused on the optimisation of the fluid flow, only works where the wet surface and topology is allowed to change significantly are included (wet and wet+dry). A whole range of works describe the topology optimisation of structural parts subjected to fluid loads, where the deformation of the structure may or may not be taken into account when computing the fluid induced loads. However, because they do not modify the wet surface and topology, they are not considered herein.

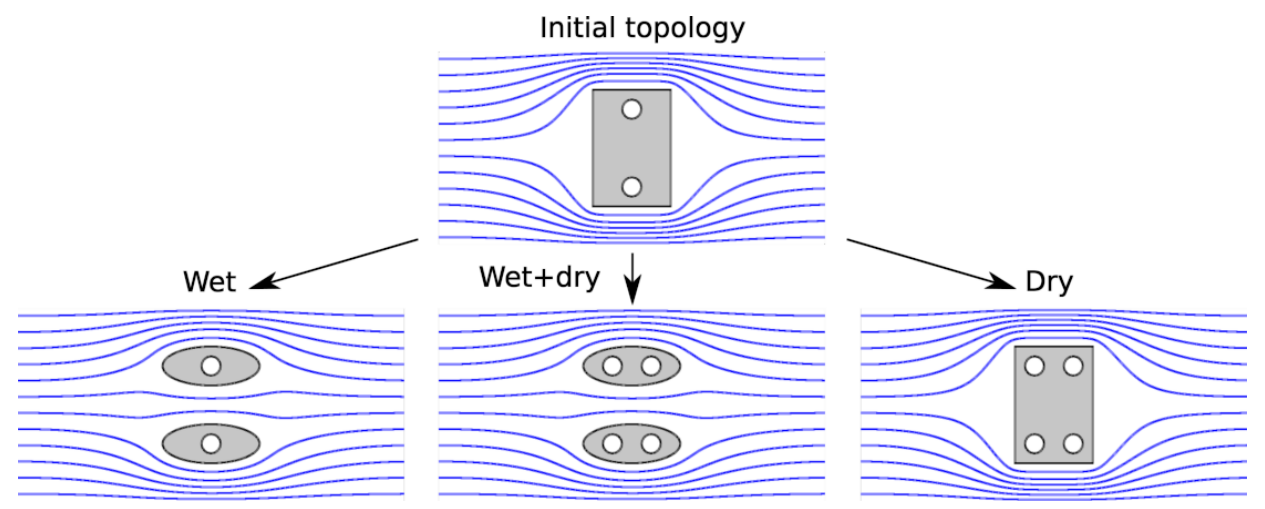

Figure 3. Description of different degrees of design modification for fluid-structure interaction (FSI) problems. 
Yoon [161] can be considered the seminal paper on topology optimisation for FSI. A unified density-based formulation of the elastic Navier-Cauchy equations assuming small strains and the incompressible Navier-Stokes equation is obtained by converting the interface condition to a volumetric integral representation, previously used for acoustic-structure interaction [162]. The fluid stress in the interaction is slightly simplified and a pressure filter function determines where the fluid pressure applies. The fluid problem is solved in the deformed mesh and a full coupling is modelled; however, the obtained deformations of the solid domain are extremely small and the two-way coupling is not really active. Another approach was taken by Kreissl et al. [163], where micro-fluidic devices are optimised subject to external mechanical actuation. A one-way coupling from structure to fluid is used to deform the fluid domain. The backward fluid-structural coupling is assumed negligible and hence ignored. Yoon [164] extends the previous work [161] to cover electro-fluid-thermal-compliant actuators, including two additional physical fields, electric and thermal, in the coupling. Planar multiphysics MEMS devices are optimised with electrical and thermal response being computed in the reference mesh. Subsequently, Yoon extended the framework to minimise the structural mass subject to stress constraints [165], and also applied the framework to the optimisation of a compliant flapper valve [166].

Jenkins and Maute [167] presented a coupled level set based framework utilising X-FEM and deformed meshes, demonstrating generalised shape optimisation of a bio-prosthetic heart valve and topology optimisation of the wall example of Yoon [161]. Munk et al. [168] present a simplified model for designing baffle plates, with a one-way pressure coupling omitting fluid shear stress. The fluid is modelled with LBM and the loads are mapped to the structural model in the reference configuration. The Bi-directional Evolutionary Structural Optimisation (BESO) method is used in a soft-kill version, but the sensitivities of changing the fluid flow are neglected. Similarly, Picelli et al. [169] also neglect the sensitivities of changing the fluid flow when updating the wet surface when applying a hard-kill BESO method to design various FSI problems.

Yoon [170] presented an extension of previous work [165], where a material failure criteria is applied to design the material distribution. Lundgaard et al. [171] revisited the unified density-based formulation of Yoon [161], however, solving the fluid in the reference mesh under the assumption of small deformations. Multiple objective functions and design problems are reviewed and thorough discussions of current limitations, artefacts and future extensions for density-based topology optimisation of FSI problems are given. Munk et al. [172] compared the previous formulation [168] to level set and density-based methods for the case of minimising the compliance of a fluid-loaded baffle plate. Subsequently, Munk et al. [173] ported the work to graphics processing unit (GPU) architecture in order to reduce the high computational time for the LBM model. Feppon et al. [174] used a level set-based framework to explicitly track and advance the interface using the Hamilton-Jacobi equation. The meshes are iteratively updated based on the convected level set by local operations, with the physics being weakly coupled, modeled in referenced configuration and solved using a staggered procedure.

\subsection{Microstructure and Porous Media}

In relation to the origin of topology optimisation, namely the homogenisation approach, there are a range of studies that consider the optimisation of material microstructures. Typically a unit-cell, or representative volume element (RVE), is subjected to periodic boundary conditions and the effective parameters are obtained by imposing a set of volumetric loads. This approach can be utilised in an inverse manner to optimise the material design and the corresponding effective parameters. For solids, this is related to the effective stiffness tensor, while for fluids this is naturally related to the permeability. For fluid-structure interaction in a porous medium, a pressure coupling term can also be obtained by homogenisation. 


\subsubsection{Material Microstructures}

Guest and Prévost [175] maximised the permeability of a porous material microstructures using a Darcy-Stokes interpolation [11] subject to isotropic symmetry constraints. The work is extended in Guest and Prévost [176] to optimise microstructures for combined maximum stiffness and permeability. Bones and tissue contain porous materials and Hollister and Lin [177] optimised tissue engineering scaffolds using a hybrid stiffness and permeability optimisation routine. $\mathrm{Xu}$ and Cheng [178] proposed a multiscale optimisation problem, where the macroscopic elastic compliance is minimised subject to a flow constraint ensuring a permeable microstructure. Physically related to this, Andreasen and Sigmund [179] optimised the microstructure of a poroelastic material for maximum poroelastic coupling during pressurisation subject to permeability constraints. Chen et al. [180] studied the optimisation of bio-scaffolds using homogenisation for tissue regeneration including permeability considerations. Chen et al. [181] extended the work to consider shear induced wall erosion. Goncalves Coelho et al. [182] introduced permeability constraints in an extensive multiscale optimisation framework for the multiscale topology optimisation of trabecular bone. For most material properties, certain bounds apply in property space and Challis et al. [183] investigated the cross-property bounds between stiffness and permeability by exploiting the Pareto-front using a level-set based approach [25].

\subsubsection{Porous Media}

In this subsection, works where the final design is supposed to be a porous structure i.e., intermediate design variables, are reviewed. This can be in terms of multiscale problems obtained e.g., by two-scale asymptotic expansion. A different take on FSI problems was presented by Andreasen and Sigmund [184] for optimisation of material design for poroelastic actuators and in Andreasen and Sigmund [185] for impact energy absorption in porous structures. Furthermore, in the context of macroscale problems, Youssef et al. [186] optimised a porous scaffold with macroscale flow channels to control the internal shear stress in a bioreactor. Ha et al. [187] used the Darcy-Stokes interpolation method [175] to maximise the permeability of three-dimensional woven materials. A multimaterial approach is taken by Wein et al. [188], where a highly nonlinear saturated porous model with multiple materials is applied to design diapers that quickly transports fluid away from the surface to capture it in the interior. Takezawa et al. [189] used a Brinkman-Forchheimer macro model to optimise material microstructures for minimum flow resistance considering the trade-off between permeability and form-drag. Lurie et al. [190] optimised the distribution of the wick (porous media used to transport condensate to the evaporator due to capillary effects) in a heat pipe. Takezawa et al. [191] applied a multiscale method to the thermofluid problem of metal printed lattice design. Effective parameters for permeability, form drag and conductivity are obtained for a generic orthogonal truss microstructure and used in a macroscopic material distribution method based on the Brinkman-Forchheimer and a convection-diffusion equation. Takezawa et al. [192] later extended this to the fluid-thermo-elastic problem of metal printed heat sinks.

\section{Quantitative Analysis}

In this section, a quantitative study of the referenced papers is carried out. In some cases, the method details might be unclear or not mentioned, excluding the paper from the statistics.

\subsection{Total Publications}

Figure 4 shows the number of papers published per year and the total accumulated number of publications over time since the inaugural paper by Borrvall and Petersson [7] in 2003. The year of publication is here taken as the year of the final journal issue. 


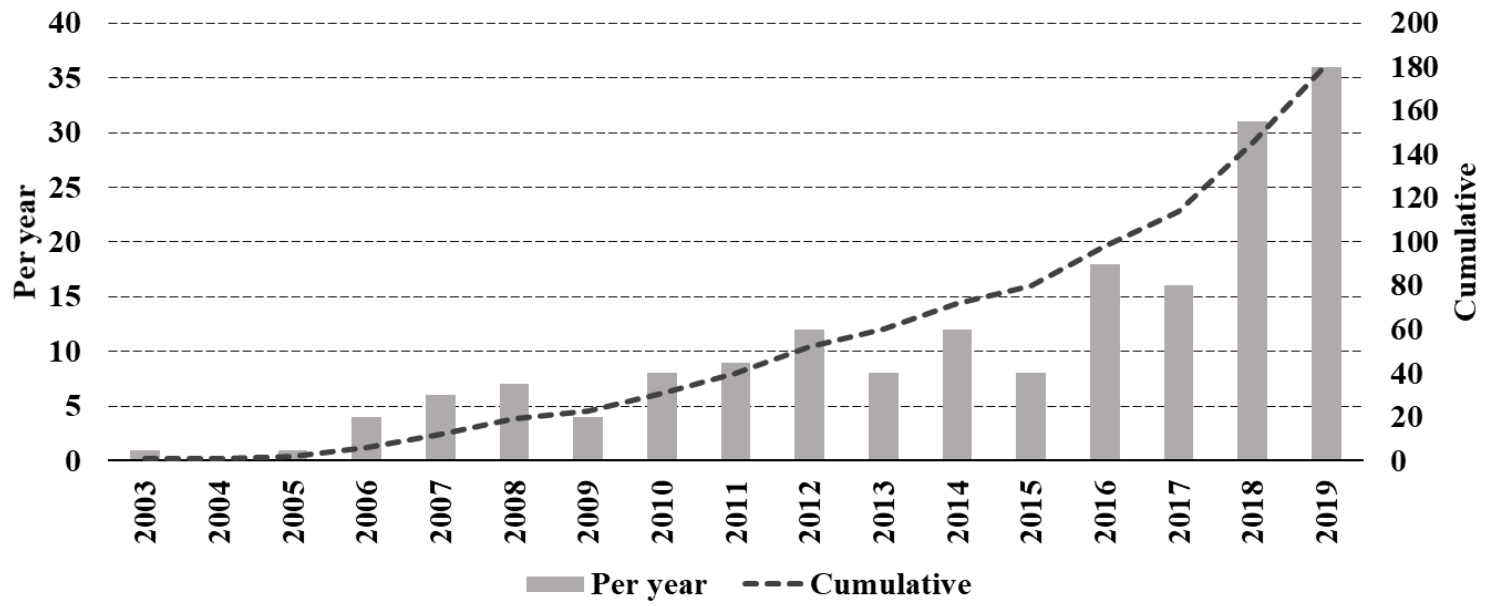

Figure 4. Number of papers published per year and total accumulated publications over time.

From 2003 to 2015, a slow increase in the number of papers per year is observed, reaching an average of 10 per year for the period 2012-2015. In 2016 and 2017, the number of papers per year almost doubled to 18 and 16, respectively, bringing the total number of publications to 100 after 2016 . In 2018 and 2019, the number of papers per year again almost doubled to 31 and 36, respectively. The total number of papers by the end of 2019 reached 182. This approximate doubling behaviour shows itself as an exponential-like increase in the number of total papers. In 2020, covering only the month of January, there have been five publications so far. This amounts to a total of 186 papers covered by this review.

\subsection{Design Representations}

As discussed in Section 1, several different design representations exist for topology optimisation. The papers are grouped into three groups: "density" covering interpolation and homogenisation approaches; "level set" covering Ersatz-material, adapted (here refering to adapted meshes and/or ignoring the solid elements in computations.) and surface-capturing level set approaches; "other" covering anything else, e.g., BESO.

Figure 5 shows how the included papers are distributed among the two main design representations, density-based approaches and level set approaches. Firstly, the use of density-based approaches vastly outnumbers any other methods with 144 papers or $77 \%$. This reflects the general tendency within the topology optimisation community to prefer density-based methods [2,3]. Secondly, the approaches relying on an implicit level set description of the geometry are also numerous at 31 papers or $17 \%$. Of these 31 papers, 11 use an Ersatz-material, 11 use an adapted approach and only nine use a surface-capturing discretisation method. Lastly, the rest of the papers are distributed as follows: 5 using BESO [168,169,172,173,177]; 2 using phase field [42,59]; 1 using a discrete surface representation [63]; 1 using a geometry-projection method [138]; and 2 utilising the topological gradient $[46,74]$.

\subsection{Discretisation Methods}

For discretising the design and physics, a variety of methods are used in the included papers: finite element method (FEM); finite volume method (FVM); lattice Boltzmann method (LBM) including Boltzmann equation related schemes; particle-based methods (PM). 


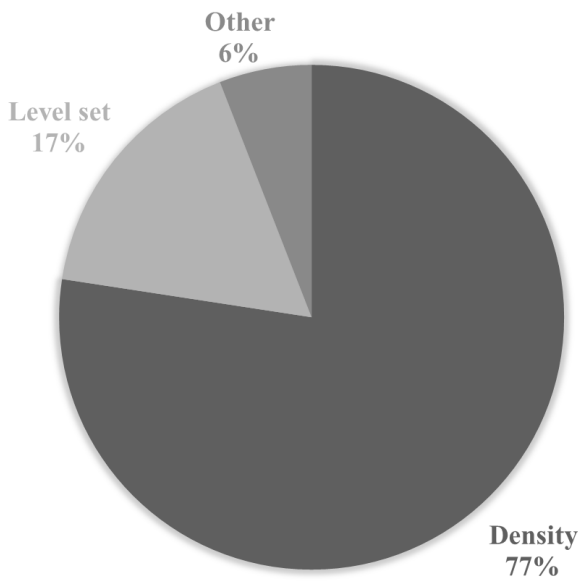

Figure 5. Distribution of papers in overall design representation type.

Figure 6 shows the distribution of papers in these overall methods. It is clear that FEM is the most widely used discretisation method with 134 papers or $76 \%$. The next most used method is LBM at 28 papers $[14,20,22,24,26,36-38,44,55,65,69,75,77,78,84,97,108,113,118,119,126,131,163,168,172,173,186]$ or $16 \%$. PM is the least used method with only a single paper [79]. Surprisingly, FVM is the second least used method with only 12 papers $[21,47,52,80,82,115,129,130,137,144,159,188]$ or $7 \%$, despite the fact that FVM for many years has been the preferred discretisation method for computational fluid dynamics. This can probably be explained by several factors: topology optimisation originates from solid mechanics where FEM is the preferred method; discrete adjoint approaches are easier using FEM than FVM; stabilised FEM has grown to be a mature and accurate method [193,194].

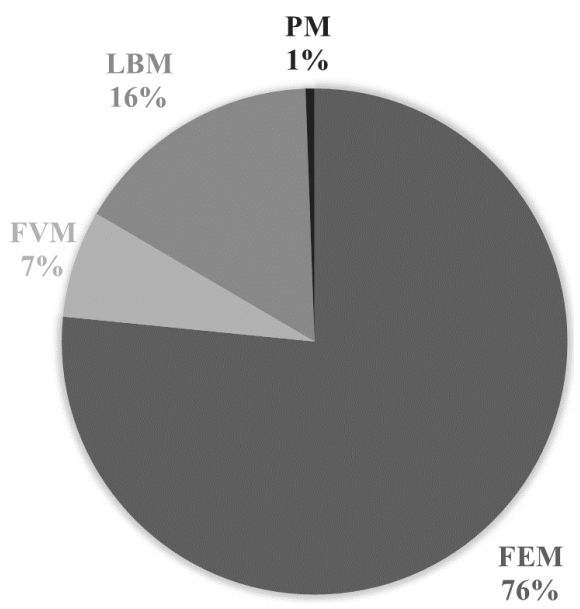

Figure 6. Distribution of papers in overall discretisation method: FEM = finite element methods; FVM = finite volume methods; LBM = lattice Boltzmann methods; PM = particle-based methods. 


\subsection{Problem Types}

The main problem types treated in this review is: pure fluid (PF); species transport (ST); conjugate heat transfer (CHT); fluid-structure interaction (FSI); microstructure and porous media (MP).

Figure 7 shows the distribution of the included papers in these problem types. It is clearly seen that the largest number of papers deal with purely fluid flow problems, namely 82 papers or $44 \%$. The second largest group deals with conjugate heat transfer covering 55 papers or $30 \%$. Species transport covers 19 papers or $10 \%$, with FSI covering 15 papers or $8 \%$, and porous media covering 14 papers or $8 \%$.

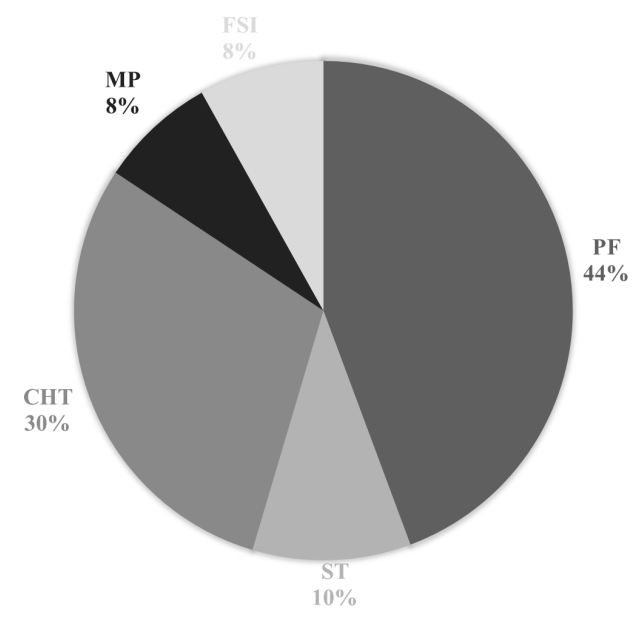

Figure 7. Distribution of papers in overall problem type: $\mathrm{PF}=$ pure fluid; $\mathrm{ST}=$ species transport; $\mathrm{CHT}=$ conjugate heat transfer; $\mathrm{FSI}=$ fluid-structure interaction; $\mathrm{MP}=$ microstructure and porous media.

\subsection{Flow Types}

In this review, the fluid model type can be boiled down to four categories: steady-state laminar flow (SS); transient laminar flow (TR); steady-state turbulent flow (TU); and Non-Newtonian fluid (NN).

Figure 8 shows the distribution of papers for fluid model type, both for (a) all papers and (b) papers treating only fluid flow. Analysing all papers, the vast majority use a steady-state laminar flow model with 158 papers or $85 \%$ as seen in Figure 8 a. Only 13 papers or $7 \%$ consider a transient laminar flow model $[72-79,145,150,152,158,188]$, with a meager six papers or $3 \%$ treating turbulent flow $[21,80-83,129]$. In the case of time-dependent problems, this is most likely due to the vast increase in computational cost related to simulation of transient flow problems, where all temporal details must be resolved sufficiently and all temporal solutions saved in memory (or recomputed) for the adjoint solve. Likewise, turbulent flow also carries an increase in computational cost with it, since turbulence models with additional degrees-of-freedom are used and fine meshes are needed to resolve the turbulent boundary layers.

All of the above use a Newtonian fluid model, but nine papers or $5 \%$ use a Non-Newtonian model [84-91,139].

Looking only at papers treating fluid flow only, Figure $8 \mathrm{~b}$ shows that the percentage of the more complex flow models increases. This indicates that more work has been done on treating transient, turbulent and non-Newtonian models for fluid flow only compared to overall for fluid-based problems. This makes sense since pure fluid flow is the obvious place to start working with and tackling the large computational cost associated with the more complex flow models. 


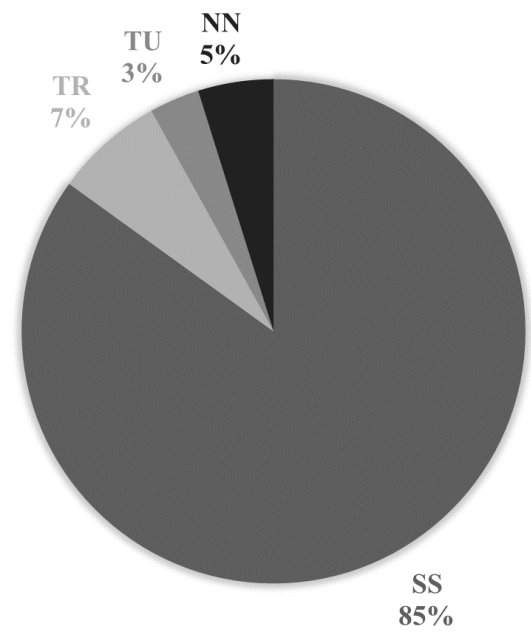

(a) All papers

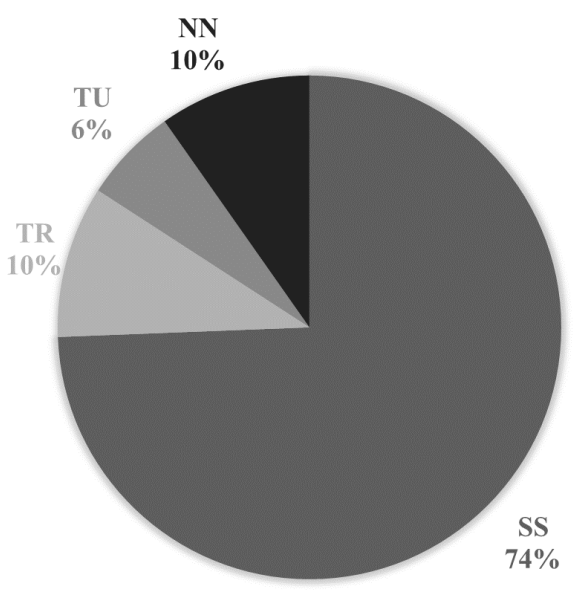

(b) Fluid flow only

Figure 8. Distribution of papers for fluid model type: SS = steady-state laminar flow; TR = transient laminar flow; $\mathrm{TU}=$ turbulent flow; $\mathrm{NN}=$ Non-Newtonian fluid.

\subsection{Three-Dimensional Problems}

A paper is classified as treating three-dimensional problems only if at least one example uses a three-dimensional model in the optimisation process. Therefore, two-dimensional results that are extruded and post-analysed in three dimensions are not included.

Figure 9 shows the distribution of papers treating two-dimensional and three-dimensional problems.

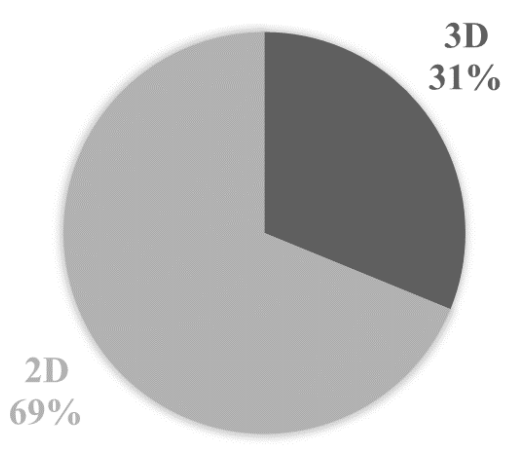

(a) Percent of all papers

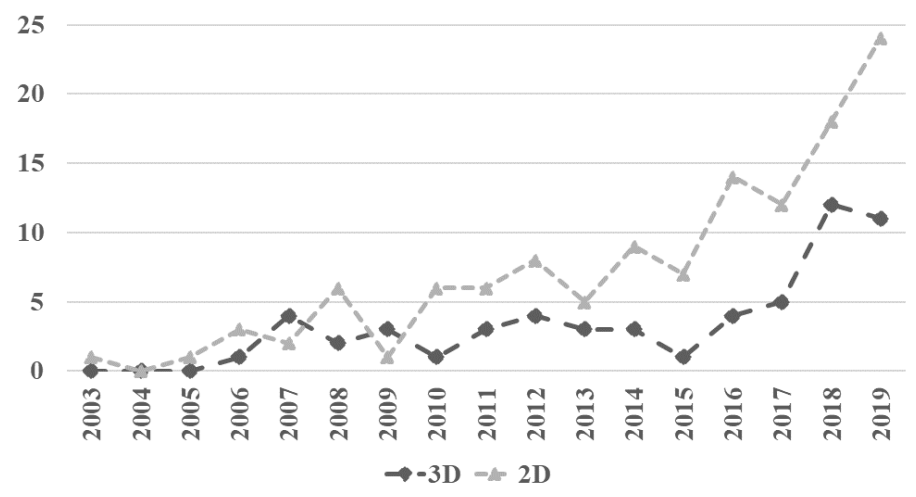

(b) Yearly publication count

Figure 9. Distribution of papers for two-dimensional (2D) and three-dimensional (3D) problems.

Figure 9a shows that a significant share of the included papers contain three-dimensional results, namely $31 \%$ or 58 out of 186 papers. For the pure fluid flow, there are 15 papers for steady laminar flow $[14,15,21,23,25,32-34,36,46,55,56,61,66,70], 3$ for unsteady flow [74,76,77], 2 for turbulent flow [80,82] and none for non-Newtonian fluids. For species transport, there are four papers $[93,98,105,107]$. For conjugate heat transfer, there are eight in forced convection $[110,117,119,122,126,129,132,135]$ and six in natural convection $[150,151,153-155,160]$. The fluid-structure interaction category counts four papers [164,168,172,173], but it must be noted that, common for all, the three-dimensional design freedom is severely limited, as the design domain is restricted in the third dimension. Finally, a very large share of the three-dimensional results belong in the category of microstructure and porous media problems with 14 papers [175-177,179-184,187-189,191,192]. Since, in material design, it is natural to consider 
both stiffness and permeability, the need for three-dimensional design freedom is obvious, as two-dimensional models would have either the fluid or the solid phase disconnected.

Figure $9 \mathrm{~b}$ shows the yearly publication count for two- and three-dimensional problems. It can be seen that they follow the same trend, which is reflected in the fact that the percentage of three-dimensional papers has been close to constant since 2010 at approximately $30 \%$. In January 2020, there has been a single three-dimensional paper [160] out of 5, making it $20 \%$ so far.

\section{Recommendations}

Based on the extensive literature review, analysis of the methods used, as well as the authors' personal experience and opinions, some recommendations are made to the research community in order to help with moving forward.

\subsection{Optimisation Methods}

Ninety-eight percent of the included papers use gradient-based optimisation approaches, covering amongst others nonlinear programming algorithms, velocity-based level set updates and discrete BESO updates. Most of these use first-order methods, with notable exceptions being the work of Evgrafov [34,41] using higher-order schemes. Only three papers use gradient-free optimisation approaches, consisting of genetic algorithms $[47,186]$ and neural networks [71]. As pointed out by Sigmund et al. [195], gradient-free approaches seldomly make sense for topology optimisation, due to the high dimensional problems for increasing design resolutions. This is perfectly illustrated in the work of Gaymann and Montomoli [71], where the design resolution is absurdly coarse and useless in practise. However, gradient-free approaches can be useful when gradient information is not available, like when using a commercial solver as a black-box, or when dealing with discontinuous functions with non-well-defined gradients. However, even in the case of black-box solvers, gradients can easily be approximated using finite differences at a fraction of the cost of most genetic algorithms. Furthermore, gradient-free methods may have advantages for multi-objective problems, although these can also be included in gradient-based approaches, e.g., [125].

However, gradient-free methods should in general be avoided for topology optimisation of fluid-based problems, and the recommendations of Sigmund [195] should be followed.

\subsection{Density-Based Approaches}

For density-based approaches, the interpolation of material properties between solid and fluid is of utmost importance to ensure final designs without intermediate design variables. Especially when moving to multiple physics, with an increasing number of material properties, the complexity of choosing the correct form of interpolation increases substantially, see, e.g., [145]. It is often not easy to intuitively choose the various interpolation functions to provide a correct relation between the material properties for intermediate design field values. Thus, it is necessary to either perform analytical derivations (often not possible) or numerical experiments. It is important to investigate the behaviour of the chosen objective functional with respect to the design field to ensure the interpolation functions provides well-scaled and monotonic behaviour $[171,196]$. Furthermore, it is extremely important to rigorously validate adjoint sensitivities with other methods, such as the complex step method or finite difference approximations as discussed by Lundgaard et al. [145].

Relying on Brinkman penalisation to model an immersed solid geometry in a unified domain has its drawbacks. Due to the nature of the penalisation, there will always exist fluid flow inside the solid. The penalisation factor must be large enough to ensure this flow is negligible inside the solid domain, but small enough to ensure numerical stability of the solution and optimisation algorithms. Generally, this is not observed to be an issue in general, except for a few very specific problems, where pressure diffusion through the solid domains are problematic $[30,66]$. However, when the pressure field is of direct interest, the Brinkman penalisation must be significantly higher to ensure an accurate evaluation [171]. 
For density-based methods and Ersatz-based level set methods on regular meshes, a smooth transition region, as ensured by e.g., density filtering, provides proper convergence of the design description with mesh refinement. It might not be an advantage to have a fully discrete $0-1$ design field, since this will lead to staircase-like descriptions of the fluid-solid interface. For coarse meshes, this may lead to flow instabilities near the interface and thus a poor description of the boundary layer. For finer meshes, this is not as big of an issue.

\subsection{Level Set-Based Approaches}

The level set method is often praised for its accurate description of the geometric interface between solid and fluid. However, if this accurate description of the interface is not transferred to the simulation model, then nothing is gained. Therefore, in order to exploit the full potential of a level set design description, it becomes essential to use surface-capturing schemes, such as e.g., X-FEM [30,150], CutFEM [76], or adaptive body-fitted meshes [89,174]. This will allow for increased accuracy of the boundary layer, which becomes increasingly important when moving to more complex fluid problems, such as turbulent flow discussed in Section 4.7. Therefore, it is recommended that future work using the level set design representation should focus on applying surface-capturing schemes with local refinement of the boundary layer regions.

\subsection{Steady-State Laminar Incompressible Flow}

A steady-state incompressible laminar flow model is used for the vast majority of the work on topology optimisation of fluid-based problems, with $85 \%$ of all papers and $74 \%$ of fluid flow only papers. With 61 papers treating steady-state incompressible fluid flow only, it is proposed that the community not spend more time on this, especially for minimum dissipated energy and pressure drop. A large range of methods have been applied to these energy-based functionals, with only a minority of papers treating more complex objective functionals such as flow distribution and uniformity $[33,50]$, diodicity $[43,53,64,68,70,91]$, minimum drag and maximum lift [29,59].

Future papers treating only steady-state incompressible fluid flow should either present novel objective functionals, constraints or applications. This should preferably be in the context of application to practical engineering applications, since the treatment of steady-state incompressible laminar flow is already rather mature.

\subsection{Benchmarking}

Future papers should build and improve upon the current literature, not reproduce it. During the development and testing phases of research, already published examples should absolutely be used as benchmarks. However, merely reproducing old examples using a new method does not represent a scientific contribution. Future papers proposing new methodologies should show clear improvements compared to the old, focusing on the extension of applicability rather than reproducing old examples. Therefore, if a new method is not or can not be shown to provide a clear improvement in one or more of the following, the work does not warrant publication:

- accuracy of the geometric representation

- precision of solution and/or optimality

- algorithmic and/or computational efficiency

- parameter robustness and algorithmic stability

If the above is not shown, then the work should not be submitted by the authors and should be rejected by reviewers. Works reinventing the wheel with a new methodology without showing clear advantages, only serves to clog up the cogs of scientific progress.

In extension of the above, when comparing methodologies in order to show a clear improvement, it is pertinent to use the exact problem setup of the previously published works. There is a tendency to 
change dimensions or physical settings slightly from paper to paper, which reduces the weight carried by the comparison.

\subsection{Time-Dependent Problems}

Only 13 papers in total treat time-dependent problems [72-79,145,150,152,158,188], eight of which are for fluid flow only. Since most realistic flow applications exhibit some form of time-dependent behaviour through either time-dependent boundary conditions or flow instabilities, it is strongly recommended that more community effort is dedicated to expanding the research on applying topology optimisation to time-dependent fluid-based problems. Due to the iterative nature of topology optimisation often requiring hundreds or thousands of simulations, the computational cost of a single time-dependent simulation becomes a significant bottleneck. The topology optimisation of time-dependent problems is therefore seen as the next frontier, requiring research into high-performance computing, efficient numerical methods and time integration and storage reduction methods. Novel ways to treat transient optimisation problems, such as the work by Chen et al. [77], can also aid in this progress. The topology optimisation community should draw inspiration from other fields, such as computational science and mathematics, and collaborate with researchers from those fields.

\subsection{Turbulent Flow}

Most industrial flow applications are turbulent, rather than laminar. Turbulence is inherently time-dependent and this research area goes hand in hand with the above. Current works on topology optimisation of turbulent flow only amount to six papers $[21,80-83,129]$ and they all consider a steady-state time-averaged approximation of turbulence, namely the Reynolds-Averaged Navier-Stokes (RANS) equations. This is a natural starting point and there is certainly still room for research to be done at this level of turbulence modelling for topology optimisation.

Capturing the turbulent boundary layers is a significant challenge in topology optimisation, since the solid-fluid interface is not known a priori and, thus, local boundary layer mesh refinement is not easily applied. This can potentially be a significant problem for density-based methods with a gradual transition from solid to fluid or with a staircase description of the boundary. Surface-capturing level set methods can potentially deliver significant benefits to this type of problems, as well as adaptive body-conforming meshes $[63,174]$ or local mesh refinement [61]. However, despite the attractive properties of accurate boundary identification, to date, only density-based methods for turbulent flow have been presented.

As will be discussed in Section 4.11, the introduction of approximate models as a surrogate for full-blown turbulent models may also be a viable way to treat very complex flow problems in the context of topology optimisation.

\subsection{Compressible Flow}

To the knowledge of the authors, no works treating fully compressible flows have been published as to the date of submission of this review paper. There are a few papers treating slightly compressible fluids, but only as an approximation of fully incompressible fluids. For this type of problem, local conservation properties may well prove important when introducing a varying design representation and, thus, methods such as FVM or Discontinuous Galerkin (DG-)FEM might be necessary to ensure conservation of mass.

\subsection{Fluid-Structure Interaction}

The efforts within wet topology optimisation of FSI problems only cover 15 papers [161,163-174], and these all remain restricted to small deformations and steady-state. Thus, the solution of the problems in the deformed state is either negligible or of minor importance to the optimisation procedure, at least if the design objective is minimum compliance. There seems to be a large 
potential in extending the methodology to transient problems exhibiting large deformations, e.g., in a biomechanical context.

\subsection{Three-Dimensional Problems}

As for time-dependent and turbulent problems, three-dimensionality is present in most industrial applications. Therefore, it is important for the community to focus on large scale three-dimensional problems. While $31 \%$ of papers treat three-dimensional problems, many of these suffer from either: being very small in the third dimension [107,122]; having severely restricted design freedom in the third dimension [164,168,172,173]; and using very coarse discretisations $[14,23,46,56,132,150]$. Truly three-dimensional problems inherently carry a large computational cost with them, and this is discussed in a number of papers, where high performance parallel computing $[15,25,33,55,76,82,126,129,151,153,160]$, graphics processing units $[119,173]$ and adaptive meshes [61] have been proposed as solutions.

Future papers treating three-dimensional problems should include a discussion of the computational cost involved. Since the research community should be moving towards more complicated flow problems including transient and turbulent flows, the concern of computational cost becomes even more dominant. Thus, even though simple problems may be treated in future papers, the computational cost and limitations of the method must be discussed in the context of tackling large scale three-dimensional problems.

\subsection{Simplified Models or Approximations}

Since all of the above problem areas all carry a large computational cost, it is beneficial for the community to work on simplified models or approximations to the complex physics.

\subsubsection{D Simplification of 3D}

It is very common in the included papers to treat two-dimensional academic problems. However, some works directly approximate a three-dimensional plane problem, with a small thickness, using a two-dimensional simplification, either stated explicitly $[43,64,67,68,106,112,116,134,140,142,143,149]$ or implicitly $[50,67,87,102,107]$. Out of these, only three papers $[106,140,143]$ include the viscous resistance from the friction due to the out-of-plane viscous boundary layers. This is despite the fact that a simple expression is given in the original works on the subject $[7,8]$. If the out-of-plane dimension is large, e.g., [152,158], the friction will go to zero. However, for small thicknesses, the friction cannot be neglected [143].

For forced convection cooling of heat sinks, pseudo-3D models have been proposed $[113,127,128,141,143]$ consisting of two layers in order to approximate the temperature of both the heat source and a cross-section of the heat sink. Furthermore, a cross-sectional model for forced convection has also been proposed for flow that is fully-developed in the out-of-plane direction [121].

Common to all of the above dimensional simplifications is that the design is assumed to be constant in the out-of-plane direction and physical fields are assumed to vary polynomially in the out-of-plane direction. However, as shown by Dilgen et al. [129], the error introduced by this assumption can be rather large and, therefore, designs must be validated.

\subsubsection{Simplified Flow Models}

A number of the included papers use a simplified flow model compared to the situation that they wish to model. One examples is to use Stokes flow instead of turbulent flow, e.g., [116]; however, this is severely limited in capturing the correct physics. One suggestion to approximate the thin boundary layers for turbulent flow is by instead using a Darcy flow model [123] with an artificial permeability in the fluid region. However, inertia is still not captured. Another recent example uses laminar flow to approximate turbulent flow in a multifidelity approximation framework [148]. For natural convection, 
a potential-like model is derived by reducing the Navier-Stokes equations by assuming the buoyancy term to be dominant $[157,160]$.

Using simplified models to treat complex problems is one way to reduce the computational cost, but it is extremely important to validate the design performance for the final design using the real model. Neglecting terms and phenomena leads to lower accuracy, but combining the simplified and full models in a sequential optimisation approach can reduce the cost significantly, while still retaining the accuracy of the full model for some steps of the optimisation. In engineering practise, a low-fidelity model is often used in the initial stages to make fast design progress and then a high-fidelity model is used to refine the design at the end [148]. However, Pollini et al. [160] recently proposed a sequential optimisation approach using the full model initially to point the gradient-based optimiser in the correct direction and then refine the design features using an approximate model.

\subsection{Numerical Verification}

For all papers treating the topology optimisation of fluid-based problems, numerical verification must be performed for the final design using an independent solver with a body-fitted mesh, sufficient mesh resolution and a fully descriptive physical model. This is a bare minimum for all future papers.

It is especially important for density- or Ersatz-material based approaches, where the boundary is not necessarily captured accurately on regular meshes. It is also important if the mesh used for optimisation is relatively coarse or where a simplified or reduced model has been used to ensure fast computations.

\subsection{Experimental Validation}

In addition to numerical verification, it is strongly suggested that, if at all possible, experimental validation is carried out, due to the complex geometries and complex physics encountered after fluid-based topology optimisation. One thing is that a simulation tool shows that the optimised geometry performs better than a reference design but should preferably be validated experimentally.

Only 12 papers, or $7 \%$, contain some form of experimental investigation of the topology-optimised designs. These cover fixed-geometry fluid diodes [43,68], small scale rotary pumps [62], forced convection heat sinks [116,128,141,146], passive coolers for light-emitting diode lamps [154,155], porous bioreactors [186], particle separators [102], and conformal cooling channels [142].

\section{Conclusions}

This review paper provides an overview of the development of topology optimisation for fluid flow and fluid-based problems. Since the seminal paper by Borrvall and Petersson [7] in 2003, 186 papers have been published treating a large variety of phenomena and component design, ranging from creeping flow in pipes and microfluidic mixers to turbulent flow and heat transfer, from steady to time-dependent flows, and from simple academic problems to real-life industrial examples. A wide range of topology optimisation methods have been applied to the field, with most being classified as density-based methods and significantly less using level set methods. This is surprising since the potential strength of level set methods, in combination with surface-capturing discretisation schemes, is to provide a better definition of the interface, which can be necessary for more complicated fluid problems. On the contrary, the limited ability to create a new topology favours the density-based methods.

Recommendations for future research directions are outlined based on the extensive literature review, the quantitative analysis, as well as the authors' personal experience and opinions. The community is encouraged to focus on moving the field to more complicated applications, such as transient, turbulent and compressible flows. Generally, previously published examples should serve only the purpose of benchmarks for verifying a new method or implementation. However, if the new method does not show clear improvements in accuracy and efficiency over the previously published 
works, it should not be published. It is suggested that published works in the future only present improvements and extensions to the previous .

Author Contributions: The two authors have contributed equally to this work. All authors have read and agreed to the published version of the manuscript.

Funding: The second author was partly funded by the InnoTop project through the Villum Foundation.

Conflicts of Interest: The authors declare no conflicts of interest.

\section{References}

1. Bendsøe, M.P.; Kikuchi, N. Generating optimal topologies in structural design using a homogenization method. Comput. Methods Appl. Mech. Eng. 1988, 71, 197-224. [CrossRef]

2. Sigmund, O.; Maute, K. Topology optimization approaches: A comparative review. Struct. Multidiscip. Optim. 2013, 48, 1031-1055. [CrossRef]

3. Deaton, J.D.; Grandhi, R.V. A survey of structural and multidisciplinary continuum topology optimization: post 2000. Struct. Multidiscip. Optim. 2014, 49, 1-38. [CrossRef]

4. Chen, X. Topology optimization of microfluidics-A review. Microchem. J. 2016, 127, 52-61. [CrossRef]

5. Dbouk, T. A review about the engineering design of optimal heat transfer systems using topology optimization. Appl. Therm. Eng. 2017, 112, 841-854. [CrossRef]

6. van Dijk, N.P.; Maute, K.; Langelaar, M.; van Keulen, F. Level-set methods for structural topology optimization: A review. Struct. Multidiscip. Optim. 2013, 48, 437-472. [CrossRef]

7. Borrvall, T.; Petersson, J. Topology optimization of fluids in Stokes flow. Int. J. Numer. Methods Fluids 2003, 41, 77-107. [CrossRef]

8. Gersborg-Hansen, A.; Sigmund, O.; Haber, R.B. Topology optimization of channel flow problems. Struct. Multidiscip. Optim. 2005, 30, 181-192. [CrossRef]

9. Evgrafov, A. The Limits of Porous Materials in the Topology Optimization of Stokes Flows. Appl. Math. Optim. 2005, 52, 263-277. [CrossRef]

10. Olesen, L.H.; Okkels, F.; Bruus, H. A high-level programming-language implementation of topology optimization applied to steady-state Navier-Stokes flow. Int. J. Numer. Methods Eng. 2006, 65, 975-1001. [CrossRef]

11. Guest, J.K.; Prévost, J.H. Topology optimization of creeping fluid flows using a Darcy-Stokes finite element. Int. J. Numer. Methods Eng. 2006, 66, 461-484. [CrossRef]

12. Evgrafov, A. Topology optimization of slightly compressible fluids. ZAMM 2006, 86, 46-62. [CrossRef]

13. Wiker, N.; Klarbring, A.; Borrvall, T. Topology optimization of regions of Darcy and Stokes flow. Int. J. Numer. Methods Eng. 2007, 69, 1374-1404. [CrossRef]

14. Pingen, G.; Evgrafov, A.; Maute, K. Topology optimization of flow domains using the lattice Boltzmann method. Struct. Multidiscip. Optim. 2007, 34, 507-524. [CrossRef]

15. Aage, N.; Poulsen, T.H.; Gersborg-Hansen, A.; Sigmund, O. Topology optimization of large scale Stokes flow problems. Struct. Multidiscip. Optim. 2007, 35, 175-180. [CrossRef]

16. Bruns, T.E. Topology optimization by penalty (TOP) method. Comput. Methods Appl. Mech. Eng. 2007, 196, 4430-4443. [CrossRef]

17. Duan, X.B.; Ma, Y.C.; Zhang, R. Shape-topology optimization for Navier-Stokes problem using variational level set method. J. Comput. Appl. Math. 2008, 222, 487-499. [CrossRef]

18. Duan, X.B.; Ma, Y.C.; Zhang, R. Shape-topology optimization of Stokes flow via variational level set method. Appl. Math. Comput. 2008, 202, 200-209. doi:10.1016/j.amc.2008.02.014. [CrossRef]

19. Duan, X.; Ma, Y.; Zhang, R. Optimal shape control of fluid flow using variational level set method. Phys. Lett. A 2008, 372, 1374-1379. doi:10.1016/j.physleta.2007.09.070. [CrossRef]

20. Evgrafov, A.; Pingen, G.; Maute, K. Topology optimization of fluid domains: kinetic theory approach. ZAMM 2008, 88, 129-141. [CrossRef]

21. Othmer, C. A continuous adjoint formulation for the computation of topological and surface sensitivities of ducted flows. Int. J. Numer. Methods Fluids 2008, 58, 861-877. [CrossRef] 
22. Pingen, G.; Evgrafov, A.; Maute, K. A parallel Schur complement solver for the solution of the adjoint steady-state lattice Boltzmann equations: application to design optimisation. Int. J. Comput. Fluid Dyn. 2008, 22, 457-464. [CrossRef]

23. Zhou, S.; Li, Q. A variational level set method for the topology optimization of steady-state Navier-Stokes flow. J. Comput. Phys. 2008, 227, 10178-10195. [CrossRef]

24. Pingen, G.; Waidmann, M.; Evgrafov, A.; Maute, K. A parametric level-set approach for topology optimization of flow domains. Struct. Multidiscip. Optim. 2010, 41, 117-131. [CrossRef]

25. Challis, V.J.; Guest, J.K. Level set topology optimization of fluids in Stokes flow. Int. J. Numer. Methods Eng. 2009, 79, 1284-1308. [CrossRef]

26. Kreissl, S.; Pingen, G.; Maute, K. An explicit level set approach for generalized shape optimization of fluids with the lattice Boltzmann method. Int. J. Numer. Methods Fluids 2011, 65, 496-519. [CrossRef]

27. Liu, Z.; Gao, Q.; Zhang, P.; Xuan, M.; Wu, Y. Topology optimization of fluid channels with flow rate equality constraints. Struct. Multidiscip. Optim. 2011, 44, 31-37. [CrossRef]

28. Okkels, F.; Dufva, M.; Bruus, H. Optimal homogenization of perfusion flows in microfluidic bio-reactors: A numerical study. PLoS ONE 2011, 6, e14574. [CrossRef]

29. Kondoh, T.; Matsumori, T.; Kawamoto, A. Drag minimization and lift maximization in laminar flows via topology optimization employing simple objective function expressions based on body force integration. Struct. Multidiscip. Optim. 2012, 45, 693-701. [CrossRef]

30. Kreissl, S.; Maute, K. Levelset based fluid topology optimization using the extended finite element method. Struct. Multidiscip. Optim. 2012, 46, 311-326. [CrossRef]

31. Deng, Y.; Liu, Z.; Wu, Y. Topology optimization of steady and unsteady incompressible Navier-Stokes flows driven by body forces. Struct. Multidiscip. Optim. 2013, 47, 555-570. [CrossRef]

32. Deng, Y.; Liu, Z.; Wu, J.; Wu, Y. Topology optimization of steady Navier-Stokes flow with body force. Comput. Methods Appl. Mech. Eng. 2013, 255, 306-321. [CrossRef]

33. Aage, N.; Lazarov, B.S. Parallel framework for topology optimization using the method of moving asymptotes. Struct. Multidiscip. Optim. 2013, 47, 493-505. [CrossRef]

34. Evgrafov, A. State space Newton's method for topology optimization. Comput. Methods Appl. Mech. Eng. 2014, 278, 272-290. [CrossRef]

35. Romero, J.S.; Silva, E.C.N. A topology optimization approach applied to laminar flow machine rotor design. Comput. Methods Appl. Mech. Eng. 2014, 279, 268-300. [CrossRef]

36. Yaji, K.; Yamada, T.; Yoshino, M.; Matsumoto, T.; Izui, K.; Nishiwaki, S. Topology optimization using the lattice Boltzmann method incorporating level set boundary expressions. J. Comput. Phys. 2014, 274, 158-181. [CrossRef]

37. Liu, Z.; Liu, G.; Geier, M.; Krafczyk, M.; Chen, T. Discrete adjoint sensitivity analysis for fluid flow topology optimization based on the generalized lattice Boltzmann method. Comput. Math. Appl. 2014, 68, 1374-1392. [CrossRef]

38. Yonekura, K.; Kanno, Y. A flow topology optimization method for steady state flow using transient information of flow field solved by lattice Boltzmann method. Struct. Multidiscip. Optim. 2015, 51, 159-172. [CrossRef]

39. Liu, X.; Zhang, B.; Sun, J. An improved implicit re-initialization method for the level set function applied to shape and topology optimization of fluid. J. Comput. Appl. Math. 2015, 281, 207-229. [CrossRef]

40. Duan, X.B.; Li, F.F.; Qin, X.Q. Adaptive mesh method for topology optimization of fluid flow. Appl. Math. Lett. 2015, 44, 40-44. [CrossRef]

41. Evgrafov, A. On Chebyshev's method for topology optimization of Stokes flows. Struct. Multidiscip. Optim. 2015, 51, 801-811. [CrossRef]

42. Garcke, H.; Hecht, C. Shape and Topology Optimization in Stokes Flow with a Phase Field Approach. Appl. Math. Optim. 2016, 73, 23-70. [CrossRef]

43. Lin, S.; Zhao, L.; Guest, J.K.; Weihs, T.P.; Liu, Z. Topology Optimization of Fixed-Geometry Fluid Diodes. J. Mech. Des. 2015, 137, 081402. [CrossRef]

44. Garcke, H.; Hecht, C.; Hinze, M.; Kahle, C. Numerical Approximation of Phase Field Based Shape and Topology Optimization for Fluids. SIAM J. Sci. Comput. 2015, 37, A1846-A1871. [CrossRef]

45. Duan, X.; Qin, X.; Li, F. Topology optimization of Stokes flow using an implicit coupled level set method. Appl. Math. Model. 2016, 40, 5431-5441. [CrossRef] 
46. N. Sá, L.F.; R. Amigo, R.C.; Novotny, A.A.; N. Silva, E.C. Topological derivatives applied to fluid flow channel design optimization problems. Struct. Multidiscip. Optim. 2016, 54, 249-264. [CrossRef]

47. Yoshimura, M.; Shimoyama, K.; Misaka, T.; Obayashi, S. Topology optimization of fluid problems using genetic algorithm assisted by the Kriging model. Int. J. Numer. Methods Eng. 2017, 109, 514-532. [CrossRef]

48. Pereira, A.; Talischi, C.; Paulino, G.H.; M. Menezes, I.F.; Carvalho, M.S. Fluid flow topology optimization in PolyTop: stability and computational implementation. Struct. Multidiscip. Optim. 2016, 54, 1345-1364. [CrossRef]

49. Duan, X.; Li, F.; Qin, X. Topology optimization of incompressible Navier-Stokes problem by level set based adaptive mesh method. Comput. Math. Appl. 2016, 72, 1131-1141. [CrossRef]

50. Kubo, S.; Yaji, K.; Yamada, T.; Izui, K.; Nishiwaki, S. A level set-based topology optimization method for optimal manifold designs with flow uniformity in plate-type microchannel reactors. Struct. Multidiscip. Optim. 2017, 55, 1311-1327. [CrossRef]

51. Jang, G.W.; Lee, J.W. Topology optimization of internal partitions in a flow-reversing chamber muffler for noise reduction. Struct. Multidiscip. Optim. 2016, 55, 2181-2196. [CrossRef]

52. Koch, J.R.L.; Papoutsis-Kiachagias, E.M.; Giannakoglou, K.C. Transition from adjoint level set topology to shape optimization for 2D fluid mechanics. Comput. Fluids 2017, 150, 123-138. [CrossRef]

53. Sato, Y.; Yaji, K.; Izui, K.; Yamada, T.; Nishiwaki, S. Topology optimization of a no-moving-part valve incorporating Pareto frontier exploration. Struct. Multidiscip. Optim. 2017, 56, 839-851. [CrossRef]

54. Sá, N.L.F.; Novotny, A.A.; Romero, J.S.; N. Silva, E.C. Design optimization of laminar flow machine rotors based on the topological derivative concept. Struct. Multidiscip. Optim. 2017, 56, 1013-1026. [CrossRef]

55. Yonekura, K.; Kanno, Y. Topology optimization method for interior flow based on transient information of the lattice Boltzmann method with a level-set function. Jpn. J. Ind. Appl. Math. 2017, 34, 611-632. [CrossRef]

56. Dai, X.; Zhang, C.; Zhang, Y.; Gulliksson, M. Topology optimization of steady Navier-Stokes flow via a piecewise constant level set method. Struct. Multidiscip. Optim. 2018, 57, 2193-2203. [CrossRef]

57. Shen, C.; Hou, L.; Zhang, E.; Lin, J. Topology optimization of three-phase interpolation models in Darcy-Stokes flow. Struct. Multidiscip. Optim. 2018, 57, 1663-1677. [CrossRef]

58. Deng, Y.; Liu, Z.; Wu, Y. Topology Optimization of Capillary, Two-Phase Flow Problems. Commun. Comput. Phys. 2017, 22, 1413-1438. [CrossRef]

59. Garcke, H.; Hinze, M.; Kahle, C.; Lam, K.F. A phase field approach to shape optimization in Navier-Stokes flow with integral state constraints. Adv. Comput. Math. 2018, 44, 1345-1383. [CrossRef]

60. Alonso, D.H.; de Sá, L.F.N.; Saenz, J.S.R.; Silva, E.C.N. Topology optimization applied to the design of 2D swirl flow devices. Struct. Multidiscip. Optim. 2018, 58, 2341-2364. [CrossRef]

61. Jensen, K.E. Topology optimization of Stokes flow on dynamic meshes using simple optimizers. Comput. Fluids 2018, 174, 66-77. [CrossRef]

62. Sá, L.F.N.; Romero, J.S.; Horikawa, O.; Silva, E.C.N. Topology optimization applied to the development of small scale pump. Struct. Multidiscip. Optim. 2018, 57, 2045-2059. [CrossRef]

63. Zhou, M.; Lian, H.; Sigmund, O.; Aage, N. Shape morphing and topology optimization of fluid channels by explicit boundary tracking. Int. J. Numer. Methods Fluids 2018, 88, 296-313. [CrossRef]

64. Shin, S.; Jeong, J.H.; Lim, D.K.; Kim, E.S. Design of SFR fluidic diode axial port using topology optimization. Nucl. Eng. Des. 2018, 338, 63-73. [CrossRef]

65. Yonekura, K.; Kanno, Y. A Heuristic Method Using Hessian Matrix for Fast Flow Topology Optimization. J. Optim. Theory Appl. 2019, 180, 671-681. [CrossRef]

66. Behrou, R.; Ranjan, R.; Guest, J.K. Adaptive topology optimization for incompressible laminar flow problems with mass flow constraints. Comput. Methods Appl. Mech. Eng. 2019, 346, 612-641. [CrossRef]

67. Alonso, D.H.; de Sá, L.F.N.; Saenz, J.S.R.; Silva, E.C.N. Topology optimization based on a two-dimensional swirl flow model of Tesla-type pump devices. Comput. Math. Appl. 2019, 77, 2499-2533. [CrossRef]

68. Lim, D.K.; Song, M.S.; Chae, H.; Kim, E.S. Topology optimization on vortex-type passive fluidic diode for advanced nuclear reactors. Nucl. Eng. Technol. 2019, 51, 1279-1288. [CrossRef]

69. Sato, A.; Yamada, T.; Izui, K.; Nishiwaki, S.; Takata, S. A topology optimization method in rarefied gas flow problems using the Boltzmann equation. J. Comput. Phys. 2019, 395, 60-84. [CrossRef]

70. Gaymann, A.; Montomoli, F.; Pietropaoli, M. Fluid topology optimization: Bio-inspired valves for aircraft engines. Int. J. Heat Fluid Flow 2019, 79, 108455. [CrossRef] 
71. Gaymann, A.; Montomoli, F. Deep Neural Network and Monte Carlo Tree Search applied to fluid-structure Topology Optimization. Sci. Rep. 2019, 9, 15916. [CrossRef] [PubMed]

72. Kreissl, S.; Pingen, G.; Maute, K. Topology optimization for unsteady flow. Int. J. Numer. Methods Eng. 2011, 87, 1229-1253. [CrossRef]

73. Deng, Y.; Liu, Z.; Zhang, P.; Liu, Y.; Wu, Y. Topology optimization of unsteady incompressible Navier-Stokes flows. J. Comput. Phys. 2011, 230, 6688-6708. [CrossRef]

74. Abdelwahed, M.; Hassine, M. Topology Optimization of Time Dependent Viscous Incompressible Flows. Abstr. Appl. Anal. 2014, 2014, 923016. [CrossRef]

75. Nørgaard, S.; Sigmund, O.; Lazarov, B. Topology optimization of unsteady flow problems using the lattice Boltzmann method. J. Comput. Phys. 2016, 307, 291-307. [CrossRef]

76. Villanueva, C.H.; Maute, K. CutFEM topology optimization of 3D laminar incompressible flow problems. Comput. Methods Appl. Mech. Eng. 2017, 320, 444-473. [CrossRef]

77. Chen, C.; Yaji, K.; Yamada, T.; Izui, K.; Nishiwaki, S. Local-in-time adjoint-based topology optimization of unsteady fluid flows using the lattice Boltzmann method. Mech. Eng. J. 2017, 4, 17-00120. [CrossRef]

78. Nørgaard, S.A.; Sagebaum, M.; Gauger, N.R.; Lazarov, B.S. Applications of automatic differentiation in topology optimization. Struct. Multidiscip. Optim. 2017, 56, 1135-1146. [CrossRef]

79. Sasaki, Y.; Sato, Y.; Yamada, T.; Izui, K.; Nishiwaki, S. Topology optimization for fluid flows using the MPS method incorporating the level set method. Comput. Fluids 2019, 188, 86-101. [CrossRef]

80. Kontoleontos, E.A.; Papoutsis-Kiachagias, E.M.; Zymaris, A.S.; Papadimitriou, D.I.; Giannakoglou, K.C. Adjoint-based constrained topology optimization for viscous flows, including heat transfer. Eng. Optim. 2013, 45, 941-961. [CrossRef]

81. Yoon, G.H. Topology optimization for turbulent flow with Spalart-Allmaras model. Comput. Methods Appl. Mech. Eng. 2016, 303, 288-311. [CrossRef]

82. Dilgen, S.B.; Dilgen, C.B.; Fuhrman, D.R.; Sigmund, O.; Lazarov, B.S. Density based topology optimization of turbulent flow heat transfer systems. Struct. Multidiscip. Optim. 2018, 57, 1905-1918. [CrossRef]

83. Yoon, G.H. Topology optimization method with finite elements based on the k- $\epsilon$ turbulence model. Comput. Methods Appl. Mech. Eng. 2020, 361, 112784. [CrossRef]

84. Pingen, G.; Maute, K. Optimal design for non-Newtonian flows using a topology optimization approach. Comput. Math. Appl. 2010, 59, 2340-2350. [CrossRef]

85. Ejlebjerg Jensen, K.; Szabo, P.; Okkels, F. Topology optimization of viscoelastic rectifiers. Appl. Phys. Lett. 2012, 100, 234102. [CrossRef]

86. Jensen, K.E.; Szabo, P.; Okkels, F. Optimization of bistable viscoelastic systems. Struct. Multidiscip. Optim. 2014, 49, 733-742. [CrossRef]

87. Hyun, J.; Wang, S.; Yang, S. Topology optimization of the shear thinning non-Newtonian fluidic systems for minimizing wall shear stress. Comput. Math. Appl. 2014, 67, 1154-1170. [CrossRef]

88. Zhang, B.; Liu, X. Topology optimization study of arterial bypass configurations using the level set method. Struct. Multidiscip. Optim. 2015, 51, 773-798. [CrossRef]

89. Zhang, B.; Liu, X.; Sun, J. Topology optimization design of non-Newtonian roller-type viscous micropumps. Struct. Multidiscip. Optim. 2016, 53, 409-424. [CrossRef]

90. Romero, J.S.; N. Silva, E.C. Non-newtonian laminar flow machine rotor design by using topology optimization. Struct. Multidiscip. Optim. 2017, 55, 1711-1732. [CrossRef]

91. Dong, X.; Liu, X. Bi-objective topology optimization of asymmetrical fixed-geometry microvalve for non-Newtonian flow. Microsyst. Technol. 2019, 25, 2471-2479. [CrossRef]

92. Okkels, F.; Bruus, H. Scaling behavior of optimally structured catalytic microfluidic reactors. Phys. Rev. E 2007, 75, 016301. [CrossRef] [PubMed]

93. Andreasen, C.S.; Gersborg, A.R.; Sigmund, O. Topology optimization of microfluidic mixers. Int. J. Numer. Methods Fluids 2009, 61, 498-513. [CrossRef]

94. Gregersen, M.M.; Okkels, F.; Bazant, M.Z.; Bruus, H. Topology and shape optimization of induced-charge electro-osmotic micropumps. New J. Phys. 2009, 11, 075019. [CrossRef]

95. Schäpper, D.; Lencastre Fernandes, R.; Lantz, A.E.; Okkels, F.; Bruus, H.; Gernaey, K.V. Topology optimized microbioreactors. Biotechnol. Bioeng. 2011, 108, 786-796. [CrossRef] [PubMed]

96. Kim, C.; Sun, H. Topology optimization of gas flow channel routes in an automotive fuel cell. Int. J. Automot. Technol. 2012, 13, 783-789. [CrossRef] 
97. Makhija, D.; Pingen, G.; Yang, R.; Maute, K. Topology optimization of multi-component flows using a multi-relaxation time lattice Boltzmann method. Comput. Fluids 2012, 67, 104-114. [CrossRef]

98. Deng, Y.; Liu, Z.; Zhang, P.; Liu, Y.; Gao, Q.; Wu, Y. A flexible layout design method for passive micromixers. Biomed. Microdevices 2012, 14, 929-945. [CrossRef]

99. Makhija, D.; Maute, K. Level set topology optimization of scalar transport problems. Struct. Multidiscip. Optim. 2014, 51, 267-285. [CrossRef]

100. Oh, S.; Wang, S.; Park, M.; Kim, J.H. Novel spacer design using topology optimization in a reverse osmosis channel. J. Fluids Eng. Trans. ASME 2014, 136, 021201. [CrossRef]

101. Chen, X.; Li, T. A novel design for passive misscromixers based on topology optimization method. Biomed. Microdevices 2016, 18, 57. [CrossRef]

102. Hyun, J.c.; Hyun, J.; Wang, S.; Yang, S. Improved pillar shape for deterministic lateral displacement separation method to maintain separation efficiency over a long period of time. Sep. Purif. Technol. 2017, 172, 258-267. [CrossRef]

103. Andreasen, C.S. Topology optimization of inertia driven dosing units. Struct. Multidiscip. Optim. 2016, 55, 1301-1309. [CrossRef]

104. Yaji, K.; Yamasaki, S.; Tsushima, S.; Suzuki, T.; Fujita, K. Topology optimization for the design of flow fields in a redox flow battery. Struct. Multidiscip. Optim. 2018, 57, 535-546. [CrossRef]

105. Guo, Y.; Xu, Y.; Deng, Y.; Liu, Z. Topology Optimization of Passive Micromixers Based on Lagrangian Mapping Method. Micromachines 2018, 9, 137. [CrossRef] [PubMed]

106. Behrou, R.; Pizzolato, A.; Forner-Cuenca, A. Topology optimization as a powerful tool to design advanced PEMFCs flow fields. Int. J. Heat Mass Transf. 2019, 135, 72-92. [CrossRef]

107. Chen, C.H.; Yaji, K.; Yamasaki, S.; Tsushima, S.; Fujita, K. Computational design of flow fields for vanadium redox flow batteries via topology optimization. J. Energy Storage 2019, 26, 100990. [CrossRef]

108. Dugast, F.; Favenne, Y.; Josset, C. Reactive fluid flow topology optimization with the multi-relaxation time lattice Boltzmann method and a level-set function. J. Comput. Phys. 2020, 109252. [CrossRef]

109. Alexandersen, J.; Aage, N.; Andreasen, C.S.; Sigmund, O. Topology optimisation for natural convection problems. Int. J. Numer. Methods Fluids 2014, 76, 699-721. [CrossRef]

110. Dede, E.M. Multiphysics Topology Optimization of Heat Transfer and Fluid Flow Systems. In Proceedings of the COMSOL Conference 2009, Boston, MA, USA, 8-10 October 2009.

111. Yoon, G.H. Topological design of heat dissipating structure with forced convective heat transfer. J. Mech. Sci. Technol. 2010, 24, 1225-1233. [CrossRef]

112. Dede, E.M. Optimization and design of a multipass branching microchannel heat sink for electronics cooling. J. Electron. Packag. Trans. ASME 2012, 134, 041001. [CrossRef]

113. McConnell, C.; Pingen, G. Multi-Layer, Pseudo 3D Thermal Topology Optimization of Heat Sinks. In Proceedings of the ASME 2012 International Mechanical Engineering Congress and Exposition, Houston, TX, USA, 9-15 November 2012; pp. 2381-2392.

114. Matsumori, T.; Kondoh, T.; Kawamoto, A.; Nomura, T. Topology optimization for fluid-thermal interaction problems under constant input power. Struct. Multidiscip. Optim. 2013, 47, 571-581. [CrossRef]

115. Marck, G.; Nemer, M.; Harion, J.L. Topology Optimization of Heat and Mass Transfer Problems: Laminar Flow. Numer. Heat Transf. Part B Fundam. 2013, 63, 508-539. [CrossRef]

116. Koga, A.A.; Lopes, E.C.C.; Villa Nova, H.F.; Lima, C.R.d.; Silva, E.C.N. Development of heat sink device by using topology optimization. Int. J. Heat Mass Transf. 2013, 64, 759-772. [CrossRef]

117. Yaji, K.; Yamada, T.; Kubo, S.; Izui, K.; Nishiwaki, S. A topology optimization method for a coupled thermal-fluid problem using level set boundary expressions. Int. J. Heat Mass Transf. 2015, 81, 878-888. [CrossRef]

118. Yaji, K.; Yamada, T.; Yoshino, M.; Matsumoto, T.; Izui, K.; Nishiwaki, S. Topology optimization in thermal-fluid flow using the lattice Boltzmann method. J. Comput. Phys. 2016, 307, 355-377. [CrossRef]

119. Łaniewski Wołłk, L.; Rokicki, J. Adjoint Lattice Boltzmann for topology optimization on multi-GPU architecture. Comput. Math. Appl. 2016, 71, 833-848. [CrossRef]

120. Qian, X.; Dede, E.M. Topology optimization of a coupled thermal-fluid system under a tangential thermal gradient constraint. Struct. Multidiscip. Optim. 2016, 54, 531-551. [CrossRef]

121. Haertel, J.H.K.; Nellis, G.F. A fully developed flow thermofluid model for topology optimization of 3D-printed air-cooled heat exchangers. Appl. Therm. Eng. 2017, 119, 10-24. [CrossRef] 
122. Pietropaoli, M.; Ahlfeld, R.; Montomoli, F.; Ciani, A.; D’Ercole, M. Design for Additive Manufacturing: Internal Channel Optimization. J. Eng. Gas Turbines Power 2017, 139, 102101. [CrossRef]

123. Zhao, X.; Zhou, M.; Sigmund, O.; Andreasen, C.S. A 'poor man's approach" to topology optimization of cooling channels based on a Darcy flow model. Int. J. Heat Mass Transf. 2018, 116, 1108-1123. [CrossRef]

124. Qian, S.; Wang, W.; Ge, C.; Lou, S.; Miao, E.; Tang, B. Topology optimization of fluid flow channel in cold plate for active phased array antenna. Struct. Multidiscip. Optim. 2018, 57, 2223-2232. [CrossRef]

125. Sato, Y.; Yaji, K.; Izui, K.; Yamada, T.; Nishiwaki, S. An Optimum Design Method for a Thermal-Fluid Device Incorporating Multiobjective Topology Optimization With an Adaptive Weighting Scheme. J. Mech. Des. 2018, 140, 31402. [CrossRef]

126. Yaji, K.; Ogino, M.; Chen, C.; Fujita, K. Large-scale topology optimization incorporating local-in-time adjoint-based method for unsteady thermal-fluid problem. Struct. Multidiscip. Optim. 2018, 58, 817-822. [CrossRef]

127. Haertel, J.H.K.; Engelbrecht, K.; Lazarov, B.S.; Sigmund, O. Topology optimization of a pseudo 3D thermofluid heat sink model. Int. J. Heat Mass Transf. 2018, 121, 1073-1088. [CrossRef]

128. Zeng, S.; Kanargi, B.; Lee, P.S. Experimental and numerical investigation of a mini channel forced air heat sink designed by topology optimization. Int. J. Heat Mass Transf. 2018, 121, 663-679. [CrossRef]

129. Dilgen, C.B.; Dilgen, S.B.; Fuhrman, D.R.; Sigmund, O.; Lazarov, B.S. Topology optimization of turbulent flows. Comput. Methods Appl. Mech. Eng. 2018, 331,363-393. [CrossRef]

130. Ramalingom, D.; Cocquet, P.H.; Bastide, A. A new interpolation technique to deal with fluid-porous media interfaces for topology optimization of heat transfer. Comput. Fluids 2018, 168, 144-158. [CrossRef]

131. Dugast, F.; Favennec, Y.; Josset, C.; Fan, Y.; Luo, L. Topology optimization of thermal fluid flows with an adjoint Lattice Boltzmann Method. J. Comput. Phys. 2018, 365, 376-404. [CrossRef]

132. Santhanakrishnan, M.S.; Tilford, T.; Bailey, C. Performance assessment of density and level-set topology optimisation methods for three-dimensional heat sink design. J. Algorithms Comput. Technol. 2018, 12, $273-287$. [CrossRef]

133. Sun, C.; Lewpiriyawong, N.; Khoo, K.L.; Zeng, S.; Lee, P.S. Thermal enhancement of fin and tube heat exchanger with guiding channels and topology optimisation. Int. J. Heat Mass Transf. 2018, 127, 1001-1013. [CrossRef]

134. Lv, Y.; Liu, S. Topology optimization and heat dissipation performance analysis of a micro-channel heat sink. Meccanica 2018, 53, 3693-3708. [CrossRef]

135. Pietropaoli, M.; Montomoli, F.; Gaymann, A. Three-dimensional fluid topology optimization for heat transfer. Struct. Multidiscip. Optim. 2019, 59, 801-812. [CrossRef]

136. Makhija, D.S.; Beran, P.S. Concurrent shape and topology optimization for steady conjugate heat transfer. Struct. Multidiscip. Optim. 2019, 59, 919-940. [CrossRef]

137. Subramaniam, V.; Dbouk, T.; Harion, J.L. Topology optimization of conjugate heat transfer systems: A competition between heat transfer enhancement and pressure drop reduction. Int. J. Heat Fluid Flow 2019, 75, 165-184. [CrossRef]

138. Yu, M.; Ruan, S.; Wang, X.; Li, Z.; Shen, C. Topology optimization of thermal-fluid problem using the MMC-based approach. Struct. Multidiscip. Optim. 2019, 60, 151-165. [CrossRef]

139. Zhang, B.; Gao, L. Topology optimization of convective heat transfer problems for non-Newtonian fluids. Struct. Multidiscip. Optim. 2019, 60, 1821-1840. [CrossRef]

140. Kobayashi, H.; Yaji, K.; Yamasaki, S.; Fujita, K. Freeform winglet design of fin-and-tube heat exchangers guided by topology optimization. Appl. Therm. Eng. 2019, 161, 114020. [CrossRef]

141. Zeng, S.; Lee, P.S. Topology optimization of liquid-cooled microchannel heat sinks: An experimental and numerical study. Int. J. Heat Mass Transf. 2019, 142, 118401. [CrossRef]

142. Jahan, S.; Wu, T.; Shin, Y.; Tovar, A.; El-Mounayri, H. Thermo-fluid Topology Optimization and Experimental Study of Conformal Cooling Channels for 3D Printed Plastic Injection Molds. Procedia Manuf. 2019, 34, 631-639. [CrossRef]

143. Yan, S.; Wang, F.; Hong, J.; Sigmund, O. Topology optimization of microchannel heat sinks using a two-layer model. Int. J. Heat Mass Transf. 2019, 143, 118462. [CrossRef]

144. Tawk, R.; Ghannam, B.; Nemer, M. Topology optimization of heat and mass transfer problems in two fluids-one solid domains. Numer. Heat Transf. Part B Fundam. 2019, 76, 130-151. [CrossRef] 
145. Lundgaard, C.; Engelbrecht, K.; Sigmund, O. A density-based topology optimization methodology for thermal energy storage systems. Struct. Multidiscip. Optim. 2019, 60, 2189-2204. [CrossRef]

146. Li, H.; Ding, X.; Meng, F.; Jing, D.; Xiong, M. Optimal design and thermal modelling for liquid-cooled heat sink based on multi-objective topology optimization: An experimental and numerical study. Int. J. Heat Mass Transf. 2019, 144, 118638. [CrossRef]

147. Dong, X.; Liu, X. Multi-objective optimal design of microchannel cooling heat sink using topology optimization method. Numeri. Heat Transf. Part A Appl. 2020, 77, 90-104. [CrossRef]

148. Yaji, K.; Yamasaki, S.; Fujita, K. Multifidelity design guided by topology optimization. Struct. Multidiscip. Optim. 2019, 61, 1071-1085. [CrossRef]

149. Hu, D.; Zhang, Z.; Li, Q. Numerical study on flow and heat transfer characteristics of microchannel designed using topological optimizations method. Sci. China Technol. Sci. 2020, 63, 105-115. [CrossRef]

150. Coffin, P.; Maute, K. A level-set method for steady-state and transient natural convection problems. Struct. Multidiscip. Optim. 2016, 53, 1047-1067. [CrossRef]

151. Alexandersen, J.; Sigmund, O.; Aage, N. Large scale three-dimensional topology optimisation of heat sinks cooled by natural convection. Int. J. Heat Mass Transf. 2016, 100, 876-891. [CrossRef]

152. Pizzolato, A.; Sharma, A.; Maute, K.; Sciacovelli, A.; Verda, V. Design of effective fins for fast PCM melting and solidification in shell-and-tube latent heat thermal energy storage through topology optimization. Appl. Energy 2017, 208, 210-227. [CrossRef]

153. Alexandersen, J.; Sigmund, O.; Meyer, K.E.; Lazarov, B.S. Design of passive coolers for light-emitting diode lamps using topology optimisation. Int. J. Heat Mass Transf. 2018, 122, 138-149. [CrossRef]

154. Lazarov, B.S.; Sigmund, O.; Meyer, K.E.; Alexandersen, J. Experimental validation of additively manufactured optimized shapes for passive cooling. Appl. Energy 2018, 226, 330-339. [CrossRef]

155. Lei, T.; Alexandersen, J.; Lazarov, B.S.; Wang, F.; Haertel, J.H.K.; De Angelis, S.; Sanna, S.; Sigmund, O.; Engelbrecht, K. Investment casting and experimental testing of heat sinks designed by topology optimization. Int. J. Heat Mass Transf. 2018, 127, 396-412. [CrossRef]

156. Saglietti, C.; Schlatter, P.; Wadbro, E.; Berggren, M.; Henningson, D.S. Topology optimization of heat sinks in a square differentially heated cavity. Int. J. Heat Fluid Flow 2018, 74, 36-52. [CrossRef]

157. Asmussen, J.; Alexandersen, J.; Sigmund, O.; Andreasen, C.S. A “poor man's” approach to topology optimization of natural convection problems. Struct. Multidiscip. Optim. 2019, 59, 1105-1124. [CrossRef]

158. Pizzolato, A.; Sharma, A.; Ge, R.; Maute, K.; Verda, V.; Sciacovelli, A. Maximization of performance in multi-tube latent heat storage-Optimization of fins topology, effect of materials selection and flow arrangements. Energy 2019, in press.

159. Ramalingom, D.; Cocquet, P.H.; Maleck, R.; Bastide, A. A multi-objective optimization problem in mixed and natural convection for a vertical channel asymmetrically heated. Struct. Multidiscip. Optim. 2019, 60, 2001-2020. [CrossRef]

160. Pollini, N.; Sigmund, O.; Andreasen, C.S.; Alexandersen, J. A “poor man's” approach for high-resolution three-dimensional topology design for natural convection problems. Adv. Eng. Softw. 2020, 140, 102736. doi:10.1016/j.advengsoft.2019.102736. [CrossRef]

161. Yoon, G.H. Topology optimization for stationary fluid-structure interaction problems using a new monolithic formulation. Int. J. Numer. Methods Eng. 2010, 82, 591-616. [CrossRef]

162. Yoon, G.H.; Jensen, J.S.; Sigmund, O. Topology optimization of acoustic-structure interaction problems using a mixed finite element formulation. Int. J. Numer. Methods Eng. 2007, 70, 1049-1075. [CrossRef]

163. Kreissl, S.; Pingen, G.; Evgrafov, A.; Maute, K. Topology optimization of flexible micro-fluidic devices. Struct. Multidiscip. Optim. 2010, 42, 495-516. [CrossRef]

164. Yoon, G.H. Topological layout design of electro-fluid-thermal-compliant actuator. Comput. Methods Appl. Mech. Eng. 2012, 209-212, 28-44. [CrossRef]

165. Yoon, G.H. Stress-based topology optimization method for steady-state fluid-structure interaction problems. Comput. Methods Appl. Mech. Eng. 2014, 278, 499-523. [CrossRef]

166. Yoon, G.H. Compliant topology optimization for planar passive flap micro valve. J. Nanosci. Nanotechnol. 2014, 14, 7585-7591. [CrossRef]

167. Jenkins, N.; Maute, K. An immersed boundary approach for shape and topology optimization of stationary fluid-structure interaction problems. Struct. Multidiscip. Optim. 2016, 54, 1191-1208. [CrossRef] 
168. Munk, D.J.; Kipouros, T.; Vio, G.A.; Steven, G.P.; Parks, G.T. Topology optimisation of micro fluidic mixers considering fluid-structure interactions with a coupled Lattice Boltzmann algorithm. J. Comput. Phys. 2017, 349, 11-32. [CrossRef]

169. Picelli, R.; Vicente, W.M.; Pavanello, R. Evolutionary topology optimization for structural compliance minimization considering design-dependent FSI loads. Finite Elem. Anal. Des. 2017, 135, 44-55. [CrossRef]

170. Yoon, G.H. Brittle and ductile failure constraints of stress-based topology optimization method for fluid-structure interactions. Comput. Math. Appl. 2017, 74, 398-419. [CrossRef]

171. Lundgaard, C.; Alexandersen, J.; Zhou, M.; Andreasen, C.S.; Sigmund, O. Revisiting density-based topology optimization for fluid-structure interaction problems. Struct. Multidiscip. Optim. 2018, 58, 969-995. [CrossRef]

172. Munk, D.J.; Kipouros, T.; Vio, G.A.; Parks, G.T.; Steven, G.P. On the effect of fluid-structure interactions and choice of algorithm in multi-physics topology optimisation. Finite Elem. Anal. Des. 2018, 145, 32-54. [CrossRef]

173. Munk, D.J.; Kipouros, T.; Vio, G.A. Multi-physics bi-directional evolutionary topology optimization on GPU-architecture. Eng. Comput. 2018, 35, 1059-1079. [CrossRef]

174. Feppon, F.; Allaire, G.; Bordeu, F.; Cortial, J.; Dapogny, C. Shape optimization of a coupled thermal fluid-structure problem in a level set mesh evolution framework. SeMA J. 2019, 76, 413-458. [CrossRef]

175. Guest, J.K.; Prévost, J.H. Design of maximum permeability material structures. Comput. Methods Appl. Mech. Eng. 2007, 196, 1006-1017. [CrossRef]

176. Guest, J.K.; Prévost, J.H. Optimizing multifunctional materials: Design of microstructures for maximized stiffness and fluid permeability. Int. J. Solids Struct. 2006, 43, 7028-7047. [CrossRef]

177. Hollister, S.J.; Lin, C.Y. Computational design of tissue engineering scaffolds. Comput. Methods Appl. Mech. Eng. 2007, 196, 2991-2998. [CrossRef]

178. Xu, S.; Cheng, G. Optimum material design of minimum structural compliance under seepage constraint. Struct. Multidiscip. Optim. 2010, 41, 575-587. [CrossRef]

179. Andreasen, C.S.; Sigmund, O. Saturated poroelastic actuators generated by topology optimization. Struct. Multidiscip. Optim. 2010, 43, 693-706. [CrossRef]

180. Chen, Y.; Zhou, S.; Li, Q. Microstructure design of biodegradable scaffold and its effect on tissue regeneration. Biomaterials 2011, 32, 5003-5014. [CrossRef]

181. Chen, Y.; Schellekens, M.; Zhou, S.; Cadman, J.; Li, W.; Appleyard, R.; Li, Q. Design Optimization of Scaffold Microstructures Using Wall Shear Stress Criterion Towards Regulated Flow-Induced Erosion. J. Biomech. Eng. 2011, 133, 081008. [CrossRef]

182. Gonçalves Coelho, P.; Rui Fernandes, P.; Carriço Rodrigues, H. Multiscale modeling of bone tissue with surface and permeability control. J. Biomech. 2011, 44, 321-329. [CrossRef]

183. Challis, V.J.; Guest, J.K.; Grotowski, J.F.; Roberts, A.P. Computationally generated cross-property bounds for stiffness and fluid permeability using topology optimization. Int. J. Solids Struct. 2012, 49, 3397-3408. [CrossRef]

184. Andreasen, C.S.; Sigmund, O. Multiscale modeling and topology optimization of poroelastic actuators. Smart Mater. Struct. 2012, 21, 065005. [CrossRef]

185. Andreasen, C.S.; Sigmund, O. Topology optimization of fluid-structure-interaction problems in poroelasticity. Comput. Methods Appl. Mech. Eng. 2013, 258, 55-62. [CrossRef]

186. Youssef, K.; Mack, J.J.; Iruela-Arispe, M.L.; Bouchard, L.S. Macro-scale topology optimization for controlling internal shear stress in a porous scaffold bioreactor. Biotechnol. Bioeng. 2012, 109, 1844-1854. [CrossRef]

187. Ha, S.H.; Lee, H.Y.; Hemker, K.J.; Guest, J.K. Topology Optimization of Three-Dimensional Woven Materials Using a Ground Structure Design Variable Representation. J. Mech. Des. 2019, 141. [CrossRef]

188. Wein, F.; Chen, N.; Iqbal, N.; Stingl, M.; Avila, M. Topology optimization of unsaturated flows in multi-material porous media: Application to a simple diaper model. Commun. Nonlinear Sci. Numer. Simul. 2019, 78, 104871. [CrossRef]

189. Takezawa, A.; Zhang, X.; Tanaka, T.; Kitamura, M. Topology optimisation of a porous unit cell in a fluid flow considering Forchheimer drag. Int. J. Comput. Fluid Dyn. 2019. [CrossRef]

190. Lurie, S.A.; Rabinskiy, L.N.; Solyaev, Y.O. Topology optimization of the wick geometry in a flat plate heat pipe. Int. J. Heat Mass Transf. 2019, 128, 239-247. [CrossRef] 
191. Takezawa, A.; Zhang, X.; Kato, M.; Kitamura, M. Method to optimize an additively-manufactured functionally-graded lattice structure for effective liquid cooling. Addit. Manuf. 2019, 28, 285-298. [CrossRef]

192. Takezawa, A.; Zhang, X.; Kitamura, M. Optimization of an additively manufactured functionally graded lattice structure with liquid cooling considering structural performances. Int. J. Heat Mass Transf. 2019, 143, 118564. [CrossRef]

193. Bazilevs, Y.; Takizawa, K.; Tezduyar, T.E. New directions and challenging computations in fluid dynamics modeling with stabilized and multiscale methods. Math. Models Methods Appl. Sci. 2015, 25, 2217-2226. [CrossRef]

194. Bazilevs, Y.; Takizawa, K.; Tezduyar, T.E. Computational analysis methods for complex unsteady flow problems. Math. Models Methods Appl. Sci. 2019, 29, 825-838. [CrossRef]

195. Sigmund, O. On the usefulness of non-gradient approaches in topology optimization. Struct. Multidiscip. Optim. 2011, 43, 589-596. [CrossRef]

196. Alexandersen, J. Topology Optimisation for Coupled Convection Problems. Master's Thesis, Technical University of Denmark (DTU), Kongens Lyngby, Denmark, 2013.

(C) 2020 by the authors. Licensee MDPI, Basel, Switzerland. This article is an open access article distributed under the terms and conditions of the Creative Commons Attribution (CC BY) license (http:/ / creativecommons.org/licenses/by/4.0/). 